\title{
Separation, Purification, Structure Analysis, In Vitro Antioxidant Activity and circRNA-miRNA-mRNA Regulatory Network on PRV-Infected RAW264.7 Cells of a Polysaccharide Derived from Arthrospira platensis
}

\author{
Mi-Xia Cao ${ }^{1,+}{ }^{+}$, Xiao-Dong Xie ${ }^{1,+}{ }^{+}$, Xin-Rui Wang ${ }^{1}$, Wen-Yue Hu ${ }^{2}$, Yi Zhao ${ }^{1}$, Qi Chen ${ }^{1}$, Lu Ji ${ }^{1}$, Ying-Yi Wei ${ }^{1}$, \\ Mei-Ling $\mathrm{Yu}^{1}$ and Ting-Jun $\mathrm{Hu}^{1, *}$ \\ 1 College of Animal Science and Technology, Guangxi University, Nanning 530004, China; \\ caomixia66668888@st.gxu.edu.cn (M.-X.C.); 1718304007@st.gxu.edu.cn (X.-D.X.); \\ 2018393054@st.gxu.edu.cn (X.-R.W.); zhaoyi@st.gxu.edu.cn (Y.Z.); chenqi@st.gxu.edu.cn (Q.C.); \\ 2018393025@st.gxu.edu.cn (L.J.); weiyingyi@gxu.edu.cn (Y.-Y.W.); yumeiling@gxu.edu.cn (M.-L.Y.) \\ 2 School of Life Sciences and Biotechnology, Shanghai Jiao Tong University, Shanghai 200030, China; \\ summer86artemis@sjtu.edu.cn \\ check for \\ updates \\ * Correspondence: tingjunhu@gxu.edu.cn; Tel.: +86-771-3235635; Fax: +86-771-3270149 \\ $+\quad$ These authors contributed equally to this work.
}

Citation: Cao, M.-X.; Xie, X.-D.; Wang, X.-R.; Hu, W.-Y.; Zhao, Y.; Chen, Q.; Ji, L.; Wei, Y.-Y.; Yu, M.-L.; $\mathrm{Hu}, \mathrm{T}$.-J. Separation, Purification, Structure Analysis, In Vitro Antioxidant Activity and circRNA-miRNA-mRNA Regulatory Network on PRV-Infected RAW264.7 Cells of a Polysaccharide Derived from Arthrospira platensis. Antioxidants 2021, 10, 1689. https://doi.org/10.3390/ antiox10111689

Academic Editor: Maria Cristina Albertini

Received: 15 August 2021

Accepted: 20 October 2021

Published: 26 October 2021

Publisher's Note: MDPI stays neutral with regard to jurisdictional claims in published maps and institutional affiliations.

Copyright: (c) 2021 by the authors. Licensee MDPI, Basel, Switzerland. This article is an open access article distributed under the terms and conditions of the Creative Commons Attribution (CC BY) license (https:/ / creativecommons.org/licenses/by/ $4.0 /)$.

\begin{abstract}
To investigate the structure of Arthrospira platensis polysaccharide (PAP) (intracellular polysaccharide) and the antioxidant activity of the first component of PAP (PAP-1) on pseudorabies virus (PRV) -infected RAW264.7 cells. The PAP was separated and purified by the Cellulose DE-52 chromatography column and Sephacryl S-200 high-resolution gel column to obtain PAP-1. The antioxidant activity and regulation of PAP-1 on PRV-infected RAW264.7 cells of circRNA-miRNA-mRNA network were investigated by chemical kit, Q-PCR, and ce-RNA seq. The results indicated that the molecular weight $(\mathrm{Mw})$ of PAP-1, which was mainly composed of glucose and eight other monosaccharides, was $1.48 \times 10^{6} \mathrm{Da}$. The main glycosidic bond structure of PAP-1 was $\left.\rightarrow 4\right)-\alpha$-D-Glcp-( $\rightarrow$. PAP-1 may be increased the antioxidant capacity by regulating the circRNA-miRNA-mRNA network in PRV-infected RAW264.7 cells. This study provided a scientific foundation for further exploring the antioxidant activity of PAP-1 based on its structure.
\end{abstract}

Keywords: Arthrospira platensis polysaccharide; pseudorabies virus; antioxidant; structure; circRNAmiRNA-mRNA

\section{Introduction}

Algal polysaccharides are natural macromolecular compounds extracted from algal and are composed of more than ten monosaccharide molecules connected by glycosidic bonds. The most commonly used method for extracting polysaccharides is the hot water extraction method, but it requires a long extraction time, high temperature, and a large amount of solvent. Therefore, researchers have improved extraction methods based on the hot water extraction method, including enzyme-assisted hot water extraction method, ultrasonic-assisted hot water extraction method, microwave-assisted hot water extraction method, freeze-thaw-assisted hot water extraction method, alkaline extraction, freeze-thawing cold-pressing, and so on [1,2]. However, different extraction methods not only affect the extraction rate but also influence the structure and biological activity of polysaccharides [2,3]. Therefore, it is necessary to screen the extraction methods to determine which is best and to ensure the structural integrity of polysaccharides when further studying their structures. In this study, the best extraction method of PAP was selected for subsequent experiments, which provided an experimental basis for further study on the structure and activity of PAP. 
At present, Arthrospira is recommended by FAO as "the most ideal food in the 21st century", while the World Health Organization calls it "the best health care product for mankind in the 21st century" [4]. PAP, as a natural health product, has no toxic and side effects and can be taken for a long time. PAP is a type of cyanobacteria, which are considered to be one of the most potent species for prevention and nutritious supplementary because of their abundant special active ingredients [5]. At present, researchers on PAP have made progress in the separation, purification, and determination of chemical structure and biological activity, but there are still many problems to be solved. Most studies have been based on crude polysaccharides, but crude polysaccharides may contain multiple mixed sugar components and small molecular impurities, so it is difficult to obtain a definitive conclusion from these studies [6-8] In addition, there have been some studies on the structure of isolated and purified PAP by FT-IR, NMR, and GC-MS, but research on the structure has not been thorough enough $[5,9,10]$. The detailed structure of polysaccharides was the foundation for studying their potential mechanisms and structure-activity relationships. In our research, the structure of PAP-1 is studied not only by FT-IR, NMR, and GC-MS, but also by specific optical rotation, periodate oxidation, smith degradation, and methylation analysis.

PRV is a double-stranded DNA herpes virus that can cause highly contagious neurological and respiratory diseases in swine and is often fatal [11]. It has caused huge economic losses to the swine industry in many countries. Most viruses, such as coronavirus disease 2019 (COVID-19), influenza virus, porcine epidemic diarrhea virus, and hepatitis C virus, cause oxidative stress when they infect cells [12-14]. High levels of reactive oxygen species (ROS) can cause serious damage to biological structures, such as cell membrane damage, DNA degeneration, and chromosome translocation. The oxidative stress caused by ROS can cause some diseases [15]. In addition to developing drug therapy, it may be a useful strategy to use dietary supplements and nutritional drugs to prevent or treat SARS-CoV-2 infection in the field of alternative and adjuvant therapy [16]. Bioactive substances in many naturally occurring foods have strong antioxidant activity. Some studies have shown that polysaccharides can reduce oxidative stress caused by adverse stimulation [17-19]. Therefore, it is still necessary to study antioxidation food and its mechanisms. Herein, PAP (intracellular polysaccharide) [20] was isolated and purified, and the effect of PAP-1 on the activity and antioxidant capacity of PRV-infected RAW264.7 cells was further investigated.

MiRNA (MicroRNA) is an endogenous single-stranded small molecular RNA with a length of about 22 nucleotides, which is widely distributed in eukaryotes, animals, and plants, and is located in the non-coding region of the genome [21]. MiRNA is a very important regulatory factor of gene expression, which mainly regulates the stability and translation efficiency of its target gene (mRNA). There are two main ways of regulation: Firstly, it is directly and completely complementary to mRNA, which leads to the degradation of the target gene (mRNA) [22]. Secondly, it can induce the target gene (mRNA) to degrade or repress its translation by forming incomplete base complementation with the 3'UTR of the target gene [23]. Some studies suggest that the Japanese encephalitis virus, dengue virus, porcine epidemic strains virus (PEDV), and other viruses could induce a significant variation of miRNA in the host, and miRNA not only regulates virus replication and pathogenicity but also adjusts the immune response of the host [24-26]. CircRNA, a closed-loop RNA molecule, is the product of gene cutting, but it participates in gene transcription and protein translation and plays an important role in the occurrence and development of tumors, neurodegenerative diseases, cardiovascular diseases, diabetes, nephropathy, arthritis, viruses, and other diseases. Therefore, it is expected to become a potential new target for diagnosis and treatment. Among its complex biological regulation functions, it mainly plays a role by competing for endogenous RNA (ceRNA): circRNA indirectly regulates the expression of the target gene of miRNA by competitively binding this miRNA [27]. Studies have shown that Chinese medicine may play an active role in the treatment of cardiovascular diseases through circRNA/miRNA/mRNA regulatory 
network [28]. With the continuous development of sequencing technology, RNA-Seq has become an effective tool for excavating and identifying new transcripts. The above studies indicate that PAP has antiviral and antioxidant effects [5,8,9], and PRV infection RAW264.7 cells may cause the differential expression of circRNA, miRNA, and mRNA [29-31]. In this study, the non-coding RNA sequencing data of PRV-infected RAW264.7 cells and PAP-1 acting on PRV-infected RAW264.7 cells from the GEO database were analyzed, and the circRNA-miRNA-mRNA network was successfully constructed, which has the characteristics of highlighting specific molecular functions and mechanisms. Then, functional enrichment analysis and annotation were carried out to further explore the potential role of circRNA, miRNA, and mRNA in the regulation of PAP-1 on PRV-infected RAW264.7 cells. The research is of great significance for PAP-1 to regulate the antioxidant capacity and circRNA-miRNA-mRNA network caused by PRV-infected RAW264.7 cells.

\section{Materials and Methods}

\subsection{Materials and Chemicals}

Arthrospira platensis (The production base of Arthrospira platensis can produce 500 tons of high-quality Arthrospira powder per 100,000 square meters of the breeding area.) was purchased from Beihai Shengbada Biotechnology Co., Ltd., (Beihai, China); Papain, Salicylic acid, Vc, DPPH, and Cellulose DEAE-52 were purchased from Beijing Solarbio Science \& Technology Co., Ltd., (Beijing, China); Sephacryl S-200 High Resolution and Dextran standards purchased from Sigma-Aldrich (Shanghai) Trading Co., Ltd., (Shanghai, China); BI fetal bovine serum was purchased from Biological Industries Israel Beit Hemek Ltd., (Nazareth, Israel); RPMI 1640 complete culture medium was purchased from ThermoFisher Biochemical Products (Beijing) Co., Ltd., (Beijing, China); CCK-8 kit was purchased from Beyotime (Shanghai, China); the Reactive Oxygen Species Assay Kit, Malondialdehyde (MDA) assay kit, Myeloperoxidase assay kit, Xanthine Oxidase (XOD) assay kit, Superoxide Dismutase (SOD) assay kit, Catalase (CAT) assay kit, and Glutathione Peroxidase (GSH-Px) assay kit were purchased from Nanjing Jiancheng Bioengineering Institute (Nanjing, China). RAW264.7 cells were purchased from the cell bank of Wuhan University. The PRV-GXLB-2013 strain was isolated, identified, and preserved by the Department of Preventive Veterinary Medicine, College of Animal Science and Technology, Guangxi University.

\subsection{Comparison of Different Extraction Methods}

\subsubsection{Different Extraction Methods of PAP}

\subsubsection{Hot Water Extraction Method}

Arthrospira platensis was extracted with distilled water at $80{ }^{\circ} \mathrm{C}$ for $4 \mathrm{~h}$. Trichloroacetic acid was dripped into the above solution to remove the protein in the extract. Then, the supernatant was obtained by centrifugation of the above solution and placed at $4{ }^{\circ} \mathrm{C}$ for $24 \mathrm{~h}$. After alcohol precipitation and centrifugation, alcohol precipitation was carried out again for $24 \mathrm{~h}$. The solution was centrifuged again, and the precipitate was washed with acetone two times. Finally, the precipitation obtained by centrifuging the above solution was dried to obtain PAP.

\subsubsection{Enzyme-Assisted Hot Water Extraction Method}

Papain (100 mg) was added to Arthrospira platensis aqueous solution (This solution contains $20 \mathrm{mg}$ of Arthrospira platensis and $200 \mathrm{~mL}$ of distilled water.) and heated at $52{ }^{\circ} \mathrm{C}$ for $1 \mathrm{~h}$ and $100{ }^{\circ} \mathrm{C}$ for $0.5 \mathrm{~h}$ to inactivate the enzyme. Then, the samples were incubated in a water bath at $80^{\circ} \mathrm{C}$ for $4 \mathrm{~h}$, and the subsequent steps were the same as those in Section 2.2.1.1. 


\subsubsection{Ultrasonication-Assisted Hot Water Extraction Method}

The Arthrospira platensis aqueous solution was treated by ultrasonication for $1 \mathrm{~h}\left(50{ }^{\circ} \mathrm{C}\right.$, $320 \mathrm{~W})$. Then, the samples were placed in a water bath at $80^{\circ} \mathrm{C}$ for $4 \mathrm{~h}$, and the remaining experimental processes were the same as those described in Section 2.2.1.1.

\subsubsection{Microwave-Assisted Hot Water Extraction Method}

The Arthrospira platensis aqueous solution was microwaved at $600 \mathrm{~W}$ for $10 \mathrm{~min}$. Then, the water bath was incubated at $80^{\circ} \mathrm{C}$ for $4 \mathrm{~h}$, and the remaining experimental processes were the same as those described in Section 2.2.1.1.

\subsubsection{Freeze-Thaw Assisted Hot Water Extraction Method}

The Arthrospira platensis aqueous solution was freeze-thawed repeatedly. Then, the samples were placed in a water bath at $80{ }^{\circ} \mathrm{C}$ for $4 \mathrm{~h}$, and the remaining experimental processes were the same as those described in Section 2.2.1.1.

\subsubsection{Comparison of Extraction Rate and Polysaccharide Content}

The weight ratio of PAP to Arthrospira platensis was considered the polysaccharide yield of PAP. The polysaccharide content of PAP was determined by the anthrone-sulfuric acid method.

\subsubsection{Comparison of Antioxidant Activity}

\subsubsection{Determination of Hydroxyl Radical Scavenging Activity}

The scavenging activities of extracts to hydroxyl free radicals were determined by an improved Cumbes-Sironoff method and Fenton method [32]. Polysaccharides and Vc solutions with different mass concentrations $(0,0.125,0.25,0.5,1.0,2.0$ and $4.0 \mathrm{mg} / \mathrm{mL})$ were prepared. Then, $9 \mathrm{mM} \mathrm{FeSO}_{4}(50 \mu \mathrm{L}), 9 \mathrm{mM}$ salicylic acid-ethanol $(50 \mu \mathrm{L})$, polysaccharide solution $(50 \mu \mathrm{L})$, and $8.8 \mathrm{mM} \mathrm{H}_{2} \mathrm{O}_{2}(50 \mu \mathrm{L})$ were added to 96-well plates. After incubation at $37^{\circ} \mathrm{C}$ for $1 \mathrm{~h}$, the absorbance at $510 \mathrm{~nm}$ was measured. The scavenging rate was calculated according to the following formula:

$$
\text { Hydroxyl radical scavenging activity }(\%)=\left[A_{0}-\left(A_{X}-A_{X 0}\right)\right] / A_{0} \times 100 \%
$$

where $A_{0}$ is the absorbance of the blank control, $A_{X}$ is the absorbance of the sample, and $A_{X 0}$ is the absorbance of the sample without $\mathrm{H}_{2} \mathrm{O}_{2}$ solution.

\subsubsection{Determination of DPPH Free Radical Scavenging Activity}

The DPPH free radical scavenging activities of polysaccharides were determined by a previously reported method [33]. DPPH (0.0082 g) was dissolved in 95\% ethanol to make a $100 \mathrm{~mL}$ solution. In addition, polysaccharides and Vc solutions were dissolved in DMSO to prepare different concentrations of inhibitor solutions $(0,0.125,0.25,0.5,1.0,2.0$, and $4.0 \mathrm{mg} / \mathrm{mL})$. The DPPH solution $(0.5 \mathrm{~mL})$ was added to different concentrations of the inhibitor solution $(0.5 \mathrm{~mL})$. The absorbance was measured at $517 \mathrm{~nm}$ after reacting in the dark at room temperature for $30 \mathrm{~min}$. The scavenging rate was calculated according to the following formula:

$$
\text { DPPH radical scavenging activity }(\%)=\left[A_{0}-\left(A_{i}-A_{i 0}\right)\right] / A_{0} \times 100 \%
$$

where $A_{0}$ is the absorbance of the blank control, $A_{i}$ is the absorbance of the sample, and $A_{i 0}$ is the absorbance of the sample without the DPPH solution.

\subsubsection{Reducing Power}

The method for the determination of reducing power is based on a previously reported method [34]. The polysaccharides and Vc solutions were dissolved in PBS to prepare solutions at different concentrations $(0,0.125,0.25,0.5,1.0,2.0$, and $4.0 \mathrm{mg} / \mathrm{mL})$. Then, 
the polysaccharide solution $(50 \mu \mathrm{L})$ and $1 \%$ potassium ferricyanide $(50 \mu \mathrm{L})$ were mixed and incubated at $50{ }^{\circ} \mathrm{C}$ for $20 \mathrm{~min}$. After incubation, the mixture was cooled to room temperature, and $10 \%$ trichloroacetic acid $(40 \mu \mathrm{L})$ was added. $\mathrm{FeCl}_{3}$ was added to the supernatant, and the absorbance was measured at $700 \mathrm{~nm}$ after $5 \mathrm{~min}$. The reducing power was calculated according to the following formula:

$$
\text { Reducing power }=A_{1}-A_{2}
$$

where $A_{1}$ is the absorbance of the sample and $A_{2}$ is the absorbance with deionized water instead of $\mathrm{FeCl}_{3}$.

\subsection{Separation and Purification of PAP}

PAP extracted by enzyme-assisted hot water extraction method was prepared into $20 \mathrm{mg} / \mathrm{mL}$ solution. PAP solution was added to a Cellulose DE-52 chromatography column $(2.0 \mathrm{~cm} \times 60 \mathrm{~cm})$ and then subsequently eluted with deionized water, $0.1,0.2,0.3$, 0.4 , and $0.5 \mathrm{M} \mathrm{NaCl}$ solution. The eluent was collected in test tubes by fraction collector, each tube was $5 \mathrm{~mL}$. The content of polysaccharides in each tube was detected by the anthrone-sulfuric acid method, and then the elution curve was drawn with the number of tubes as abscissa and the content of polysaccharide as ordinate. The main absorption peaks were mixed according to the polysaccharide content of the eluent. $\mathrm{NaCl}$ was removed by dialysis in deionized water, and the purified polysaccharides were obtained by vacuum freeze-drying. Then, each component separated and purified by Cellulose DE-52 chromatography column was further purified by a Sephacryl S-200 high-resolution gel column $(1.7 \mathrm{~cm} \times 100 \mathrm{~cm})$. The polysaccharide content of the eluent was also detected, and the absorption peaks were combined and finally freeze-dried.

\subsection{Comparison of Antioxidant Activity of PAP}

The methods of scavenging hydroxyl radicals, DPPH radicals, and reducing power were the same as those described in Section 2.2.3.

\subsection{Structure Analysis of the First Component of PAP (PAP-1)}

\subsubsection{Determination of Molecular Weight}

Dextran standards $(5 \mathrm{mg} / \mathrm{mL})$ with different molecular weights $(1152,5000,11,600$, $23,800,48,600,80,900,148,000,273,000,409,800$, and 667,800 Da) and PAP-1 were centrifuged and filtered. The purity of PAP-1 was identified, and its molecular weight was determined by HPGPC. The conditions were as follows: Chromatographic column: BRT105-104-102 gel column $(8 \times 300$ mm) (BoRui Saccharide, BRT105-104-102, Yangzhou, China); mobile phase: $0.05 \mathrm{M} \mathrm{NaCl}$; flow rate: $0.6 \mathrm{~mL} / \mathrm{min}$; column temperature: $40{ }^{\circ} \mathrm{C}$; sample size: $20 \mu \mathrm{L}$; detector: differential detector RI-502 (Shimadzu (China) Co., Ltd., RI-502, Guangzhou, China).

\subsubsection{Specific Rotation}

The optical intensity of PAP-1 $(0.4 \mathrm{mg} / \mathrm{mL})$ was measured by a digital automatic polarimeter (Shanghai Precision Scientific Instruments Co., Ltd., WZZ-2S, Shanghai, China) at $20^{\circ} \mathrm{C}$.

\subsubsection{FT-IR}

PAP-1 was mixed with $\mathrm{KBr}$ and pressed into thin slices, which were scanned by FT-IR (Thermo Scientific, Nicolet iS50, New York, NY, USA) in the range of $4000 \sim 400 \mathrm{~cm}^{-1}$.

\subsubsection{Monosaccharide Composition Analysis}

PAP-1 (5 mg) was dissolved in $2 \mathrm{M}$ trifluoroacetic acid ( $2 \mathrm{~mL}$ ) and then hydrolyzed at $121{ }^{\circ} \mathrm{C}$ for $2 \mathrm{~h}$, but the standard solutions have not been hydrolyzed by trifluoroacetic acid. Nitrogen was introduced into the acidolysis solution and blown dry. The pow- 
der was cleaned with methanol repeatedly and blown dry three times to remove the trifluoroacetic acid. The obtained dry powder was dissolved in distilled water and transferred to a chromatographic bottle for determination. Galacturonic acid, glucuronic acid, 6-Deoxy-L-mannosehydrat, arabinose, fucose, mannose, galactose, glucose, fructose, xylose, and ribose were prepared in 1, 10, 20, 30, 40, and $50 \mu \mathrm{g} / \mathrm{mL}$ solutions, respectively. The standard can be directly analyzed on the machine without derivation. The adopted chromatographic system was a Thermo ICS-5000+ ion chromatographic system (Thermo Fisher Scientific, ICS-5000+, New York, NY, USA). The chromatographic conditions were as follows: Dionex ${ }^{\mathrm{TM}}$ CarboPac $^{\mathrm{TM}}$ PA20 liquid chromatography column; sample size: $20 \mu \mathrm{L}$; mobile phase $\mathrm{A}$ : $\mathrm{H}_{2} \mathrm{O}$; mobile phase B: $100 \mathrm{mM} \mathrm{NaOH}$; column temperature: $30^{\circ} \mathrm{C}$. The monosaccharide components were detected by the electrochemical detector (HPLC-DAD) (Shimadzu (China) Co., Ltd., Shimadzu LC-10A, Guangzhou, China).

\subsubsection{Periodate Oxidation and Smith Degradation}

PAP-1 (50 mg) was oxidized with $15 \mathrm{mM} \mathrm{NaIO}_{4}(25 \mathrm{~mL})$ and then reacted at $4{ }^{\circ} \mathrm{C}$ in the dark. The absorbance was measured at $223 \mathrm{~nm}$ every $4 \mathrm{~h}$ until it reached a stable value. The consumption of periodic acid was calculated according to the standard curve of $\mathrm{NaIO}_{4}$. The yield of formic acid was determined by titration with $0.053 \mathrm{M} \mathrm{NaOH}$. Then, ethylene glycol was added to terminate the periodic acid reaction. The oxidized products of periodate were dialyzed in water for $48 \mathrm{~h}$ and reduced by adding $\mathrm{NaBH}_{4}$ (50 mg) for $12 \mathrm{~h}$. Then, acetic acid was added to adjust the $\mathrm{pH}$, and the solution was dialyzed in deionized water for $48 \mathrm{~h}$. The residue was completely hydrolyzed with $2 \mathrm{M}$ trifluoroacetic acid. Methanol was repeatedly added and dried to remove trifluoroacetic acid. Finally, the product was acetylated and analyzed by GC (Agilent Technologies lnc., Agilent 7820A; Santa Clara, CA, USA) [35].

\subsubsection{Methylation Analysis}

PAP-1 (1 mg) was methylated so that all the free hydroxyl groups were methylated by the Hakomori method. Infrared spectroscopy is used to detect the absorption at $3500 \mathrm{~cm}^{-1}$ to determine whether the methylation reaction is complete. Then, $2 \mathrm{M}$ trifluoroacetic acid $(100 \mu \mathrm{L})$ was added and hydrolyzed at $121^{\circ} \mathrm{C}$ for $90 \mathrm{~min}$ to obtain a partially methylated monosaccharide. These monosaccharides were reduced and acetylated, and the methylene chloride phase in the lower layer contained partially methylated alditol acetate. The above derivatives were analyzed by GC-MS, and the connection mode of the glycosidic bond was obtained by analyzing the peak sequence in GC and the main ion fragments of MS. Mass spectrometry conditions were as follows: PAP-1 was detected by electron bombardment ion source (EI) in full SCAN mode, and the mass scanning range (m/z) was 30-600 (Agilent Technologies lnc., Agilent 5977B; Santa Clara, CA, USA). Gas chromatography conditions: $140{ }^{\circ} \mathrm{C}$ for $2.0 \mathrm{~min}, 3^{\circ} \mathrm{C} / \mathrm{min}$ to $230{ }^{\circ} \mathrm{C}$ for $3 \mathrm{~min}$, and the injection volume was $1 \mu \mathrm{L}$ (Agilent Technologies lnc., Agilent 7820A; Santa Clara, CA, USA).

\subsubsection{NMR Analysis}

PAP-1 (50 mg) was dissolved in $\mathrm{D}_{2} \mathrm{O}(0.5 \mathrm{~mL})$ and freeze-dried into powder (this process was repeated to fully exchange active hydrogen). The ${ }^{1} \mathrm{H}-\mathrm{NMR},{ }^{13} \mathrm{C}-\mathrm{NMR}$, one-dimensional spectrum, and two-dimensional spectrum of DEPT135 in which PAP-1 was dissolved in $\mathrm{D}_{2} \mathrm{O}$ were measured by a $600 \mathrm{MHz}$ NMR spectrometer (Bruker Scientific Technology (Shanghai) Co., Ltd., Bruker AVANCE III HD600, Shanghai, China) at $25^{\circ} \mathrm{C}$.

\subsection{The Effect of PAP-1 on Antioxidation of PRV-Infected RAW264.7 Cells}

\subsubsection{The Effect of PAP-1 on the Activity of RAW264.7 Cells}

RAW264.7 cells at a concentration of $1 \times 10^{6}$ cell $/ \mathrm{mL}$ were added to 96-well culture plates. They were divided into a blank group, cell group, and PAP-1 groups $(25,50,100$, 200, 400, 800, and $1600 \mu \mathrm{g} / \mathrm{mL})$. Culture medium $(100 \mu \mathrm{L})$ was added to the cell group, PAP-1 solution at different concentrations was added to the PAP-1 groups, and the cells 
were cultured for $8 \mathrm{~h}, 12 \mathrm{~h}, 24 \mathrm{~h}$, or $48 \mathrm{~h}$. Cell counting kit-8 (CCK-8) assay was used to detect cell activity [36]. Add the CCK-8 solution $(10 \mu \mathrm{L})$ to each well of 96 -well plates, then put them in an incubator to incubate for $1-4 \mathrm{~h}$, and finally use a microplate reader (Tecan (Shanghai) Trading Co., Ltd., Infinite M200 Pro, Zürich, Switzerland) to detect the absorbance at $450 \mathrm{~nm}$.

\subsubsection{The Effect of PAP-1 on the Activity of PRV-Infected RAW264.7 Cells}

The following groups were used: blank group, cell group, PRV group, and PAP-1 groups $(25,50,100,200$, and $400 \mu \mathrm{g} / \mathrm{mL})$. Cell culture medium $(100 \mu \mathrm{L})$ was added to the cell group, and PRV solution $(100 \mu \mathrm{L})$ was added to the other groups and incubated for $2 \mathrm{~h}$ in 96-well culture plates. The supernatant was discarded, and the cells were washed with PBS three times. Culture medium was added to the cell group and PRV group, while PAP-1 solution $(100 \mu \mathrm{L})$ was added to the PAP-1 groups. They were cultured for $8 \mathrm{~h}, 12 \mathrm{~h}, 24 \mathrm{~h}$, or $48 \mathrm{~h}$, and the cell activity was detected by the CCK-8 method.

\subsubsection{The Effect of PAP-1 on the Antioxidative Capacity in PRV-Infected RAW264.7 Cells}

This experiment included the cell group, PRV group, and PAP-1 groups (50, 100, and $200 \mu \mathrm{g} / \mathrm{mL}$ ) (96-well culture plates). The steps of incubating PRV and adding PAP-1 solution were the same as those in Section 2.6.2. The supernatant was discarded, and the cells were washed with PBS three times. DCFH-DA fluorescent probe $(100 \mu \mathrm{L})$ was added to each well and incubated for $30 \mathrm{~min}$. Finally, PBS $(100 \mu \mathrm{L})$ was added to each well to remove the cells, and then the absorbance was measured at an excitation wavelength of $488 \mathrm{~nm}$ and an emission wavelength of $525 \mathrm{~nm}$ according to the Reactive Oxygen Species Assay Kit.

This experiment also included the cell group, PRV group, and PAP-1 groups (50, 100, and $200 \mu \mathrm{g} / \mathrm{mL}$ ) (6-well culture plates). The steps of incubating PRV and adding PAP-1 solution were the same as those in Section 2.6.2. The supernatant was used to measure MDA level, and the cells were washed with PBS three times. Add PBS $(500 \mu \mathrm{L})$ to each well, scrape off the cells, crush the cells with a cell ultrasonic breaker (Ningbo Scientz Biotechnology Co., Ltd., SCIENTZ-IID, Ningbo, China), centrifuge at $3000 \mathrm{rpm}$ for $10 \mathrm{~min}$, and then take the supernatant to measure the activities of GSH-Px, SOD, MPO, $\mathrm{XOD}$, and CAT in the cells. The experiment was carried out in strict accordance with the instructions of the kits.

\subsubsection{CeRNA-Seq}

CircRNA-miRNA-mRNA regulatory network was constructed by ceRNA-seq to further explore the antioxidant regulatory effect of PAP-1 on PRV-infected RAW264.7 cells. The experiment was divided into three groups, which were PAP-1 group $(200 \mu \mathrm{g} / \mathrm{mL})$, PRV group, and cell group, with three replicates in each group (When performing ceRNASeq, each group was labeled for convenience. " $\mathrm{C}$ " is the abbreviation of cell, " $\mathrm{V}$ " is the abbreviation of virus, and " $\mathrm{M}$ " is the abbreviation of medicine. Therefore, the PAP-1 group, PRV group, and cell group are marked as CVM group, CV group, and C group, respectively). RAW264.7 cells at a concentration of $1 \times 10^{6}$ cells $/ \mathrm{mL}$ were added into a 6-well plate. After incubation for $8 \mathrm{~h}$ at $37^{\circ} \mathrm{C}$ with $5 \% \mathrm{CO}_{2}, \mathrm{PRV}$ solution was added and incubated for $2 \mathrm{~h}$. The virus solution was discarded and washed with PBS three times. Finally, PAP-1 was added and incubated for $12 \mathrm{~h}$. Cell samples were collected, and the ceRNA-seq was completed by Guangzhou Gidio Biotechnology Co., Ltd. The constructed sequencing library was sequenced with Illumina HiSeqTM 4000 to find the differentially expressed circRNA, miRNA, and mRNA among the three groups of PAP-1 group, PRV group, and cell group. According to the sequence of circRNA, the targetScan 7.2 is used to predict the interaction with miRNA, and then combined with the regulatory relationship between miRNA and genes in the miRTarBase and miRBase databases, Cytoscape 3.7.1 software is used to construct a circRNA-miRNA-mRNA regulatory network. Finally, Gene Ontology 
and $\mathrm{KO}$ enrichment analysis were performed on the mRNA differentially expressed in the $\mathrm{C}$ group and the $\mathrm{CV}$ group, and the $\mathrm{CV}$ group and the CVM group.

\subsubsection{Quantitative Real-Time PCR}

RAW264.7 cells treatment was the same as the second experiment in Section 2.6.3. The total RNA of RAW264.7 cells was extracted by Trizol reagent according to the manufacturer's instructions. cDNA was synthesized with the $5 \times$ All-In-One RT MasterMix with AccuRT (Lot. 0229854828001, abm). Quantitative real-time PCR EvaGreen $2 \times$ qPCR MasterMix-No Dye (Lot. 10518551127002, abm). The mRNA expression levels of MPO, XOD, SOD, and GSH-Px were detected by Q-PCR.

\subsection{Statistical Analysis}

The data were analyzed by SPSS 22.0, and the results include the mean \pm SD. One-way analysis of variance (ANOVA) was used for comparisons among groups, and the LSD-t-test was used for pairwise comparisons among groups.

\section{Results and Discussion}

\subsection{Comparison of Different Extraction Methods}

In this study, the extraction rate and contents of polysaccharides processed by the three extraction methods except for the microwave-assisted hot water extraction method were significantly higher than those processed by the hot water extraction method (Figure 1A,B) $(p<0.05$ or $p<0.01)$. Scavenging hydroxyl radicals, DPPH radicals, and reducing power are important indexes to evaluate the antioxidant activity of polysaccharides [37]. The scavenging capacity of PAP increased rapidly and then slowly with increasing concentration, which was consistent with a previous research method [38]. The order of scavenging of hydroxyl radicals by different extraction methods, DPPH radicals, and reducing power from strong to weak was enzyme-assisted hot water extraction method $>$ freezethaw assisted hot water extraction method $>$ microwave-assisted hot water extraction method $>$ ultrasonic-assisted hot water extraction method $>$ hot water extraction method (Figure 1C-E). Compared with other methods, the enzyme-assisted hot water extraction method had the advantages of mild reaction conditions, high extraction rate, less damage to polysaccharide structure, avoid changing the biological activity of polysaccharides, low cost, energy savings, and environmental protection [39]. Therefore, the PAP obtained by the enzyme-assisted hot water extraction method was selected for subsequent experiments.

\subsection{Isolation and Purification}

The PAP obtained by the enzyme-assisted hot water extraction method was separated into five peaks by a Cellulose DE-52 chromatography column; that is, it mainly contained five polysaccharide components (PAPs) (Figure 2A). After further purification by a Sephacryl S-200 High-Resolution chromatography column, each component showed a single symmetrical elution peak, indicating that the molecular weights of PAPs were uniform (Figure 2B-F). The polysaccharide contents of PAPs were significantly higher than those of PAP $(p<0.01)$ (Figure 2G), and the results were similar to that of Ren et al. [40]. The yield of PAP- 1 was the highest of the PAPs, so the structure of PAP-1 was analyzed in detail in this study.

\subsection{Determination of the Antioxidant Activity of PAPS}

From Figure $3 \mathrm{~A}-\mathrm{C}$, the antioxidant activities of PAPs showed a dose-dependent relationship with the concentration. The order of scavenging hydroxyl radicals, DPPH radicals, and reducing power from strong to weak was PAP-3 > PAP-1 > PAP-4 $>$ PAP-5 > PAP-2. Overall, the antioxidant activities of PAPs were different; this trend is consistent with the results of Chen et al. [38]. 
A

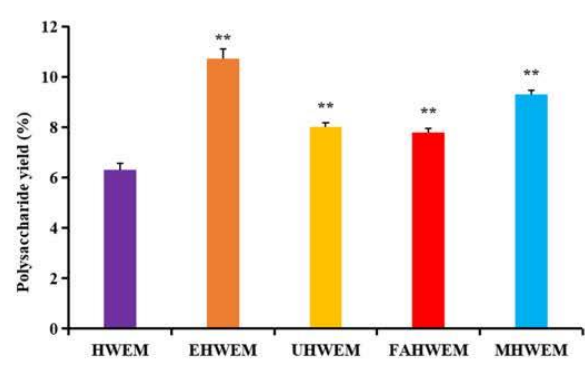

C

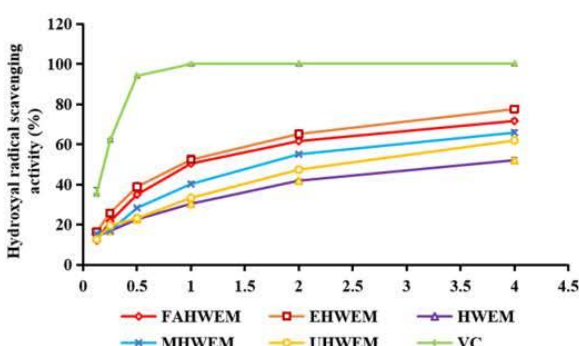

D

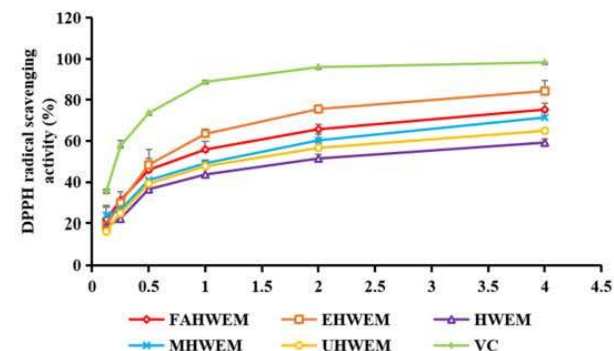

$\mathbf{E}$

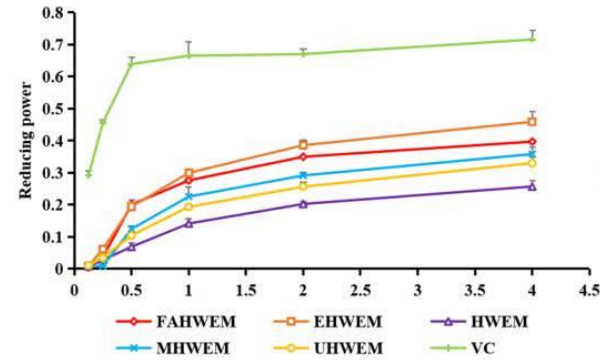

B
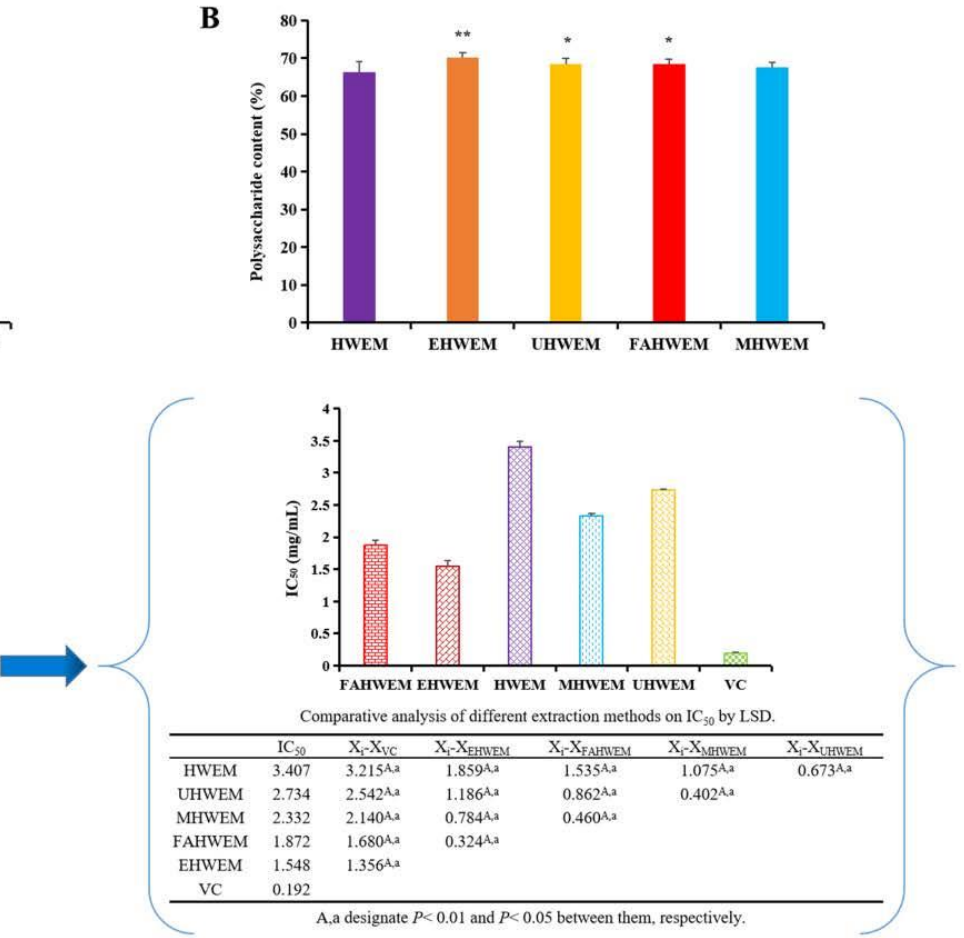

A, a designate $P<0.01$ and $P<0.05$ between them, respectively.
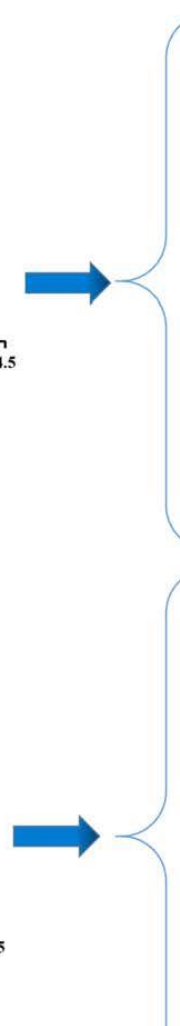

A,a designate $P<0.01$ and $P<0.05$ between them, respectively.

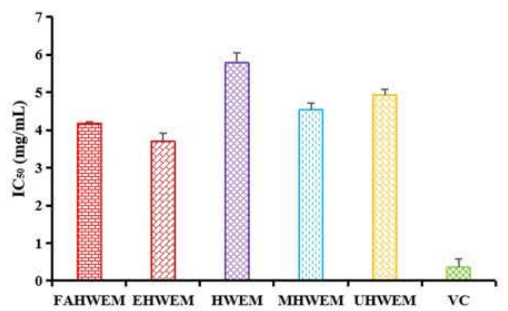

Comparative analysis of different extraction methods on IC $\mathrm{s}_{\mathrm{s}}$ by LSD

\begin{tabular}{|c|c|c|c|c|c|c|}
\hline $\begin{array}{l}\text { Methods } \\
\end{array}$ & $\mathrm{IC}_{50}$ & $\mathrm{X}_{1}-\mathrm{X}_{\mathrm{VC}}$ & $\mathrm{X}_{1}-\mathrm{X}_{\mathrm{EHWEM}}$ & $\mathrm{X}_{1}-\mathrm{X}_{\text {FAнHUEM }}$ & $\mathrm{X}_{1}-\mathrm{X}_{\mathrm{MHWEN}}$ & $\mathrm{X}_{i}-\mathrm{X}_{\text {UHWEM }}$ \\
\hline HWEM & 5.781 & $5.422^{\AA, 2}$ & $2.081^{A, A}$ & $1.601^{\mathrm{A}, 2}$ & $1.245^{\mathrm{A}, \mathrm{a}}$ & $0.845^{A, a}$ \\
\hline UHWEM & 4.936 & $4.577^{\mathrm{A}, \mathrm{A}}$ & $1.236 \mathrm{Am}$ & $0.756 A^{2,2}$ & $0.400^{2}$ & \\
\hline MHWEM & 4.536 & $4.177^{\mathrm{A}, \mathrm{a}}$ & $0.836^{\mathrm{Aa}}$ & $0.356^{\mathrm{a}}$ & & \\
\hline FAHWEM & 4.180 & $3.821^{A, a}$ & $0.48^{\mathrm{A}, \mathrm{a}}$ & & & \\
\hline EHWEM & 3.700 & $3.341^{A, a}$ & & & & \\
\hline vc & 0.359 & & & & & \\
\hline
\end{tabular}

Figure 1. Comparison of polysaccharide yield (A) (means $\pm \mathrm{SD}, n=9$ ), polysaccharide content (B) (means $\pm \mathrm{SD}, n=9$ ), and antioxidant activity (C-E) (means $\pm \mathrm{SD}, n=3$ ) of PAP were obtained by different extraction methods. HWEM, hot water extraction method; EHWEM, enzyme-assisted hot water extraction method; UHWEM, ultrasonic-assisted hot water extraction; MHWEM, microwave-assisted hot water extraction; FAHWEM, freeze-thaw assisted hot water extraction. Bars with * and $* *$ indicate significant difference or most significant difference with the HWEM group, respectively $(p<0.05$ or $p<0.01)$. "A, a" designate $p<0.05$ or $p<0.01$ between them. 
A

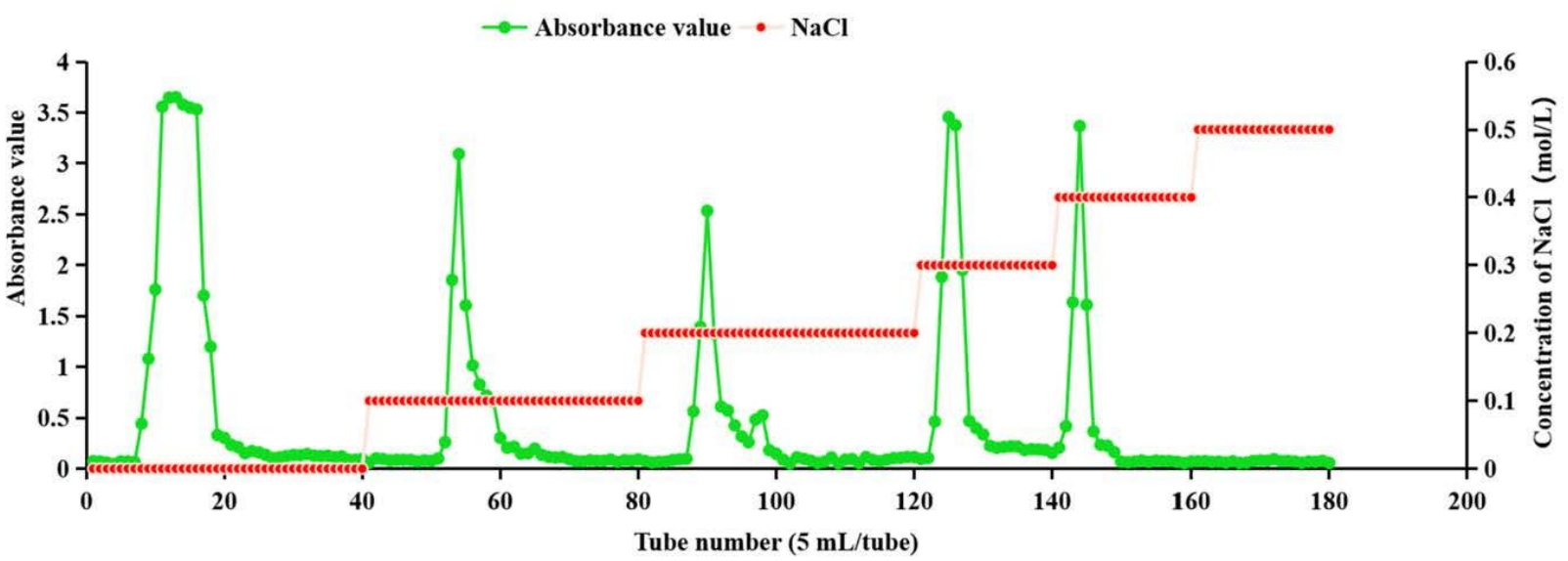

B

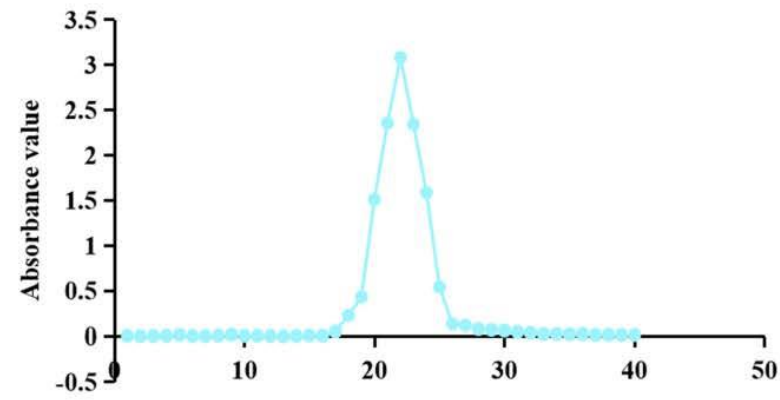

D

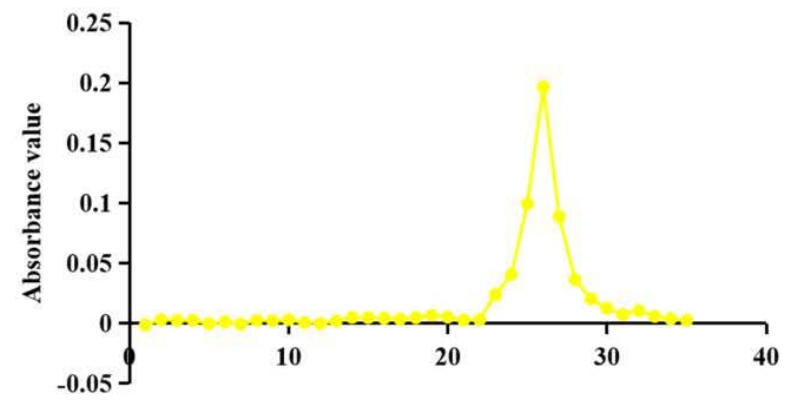

F

PAP-5

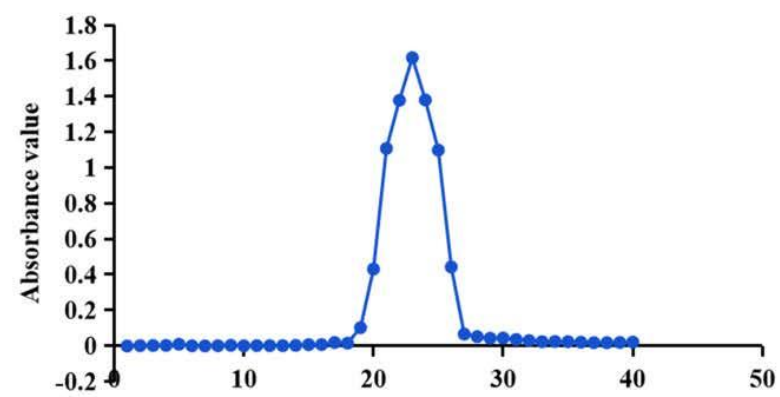

C

PAP-2

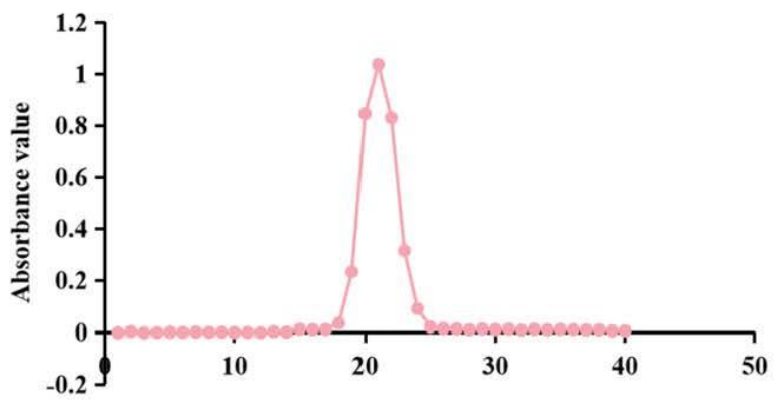

E

PAP-4

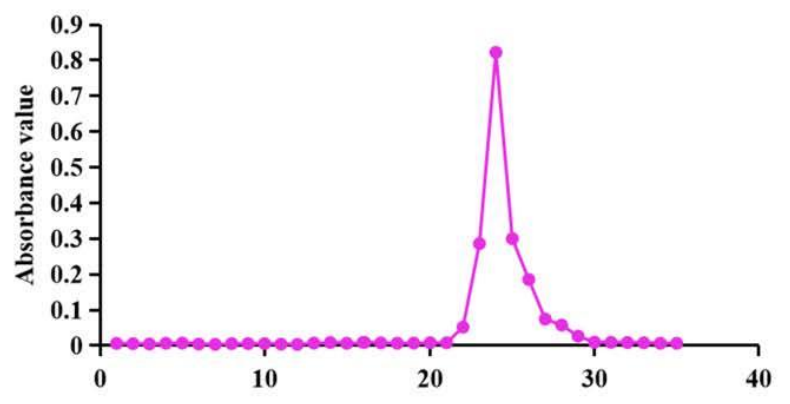

G

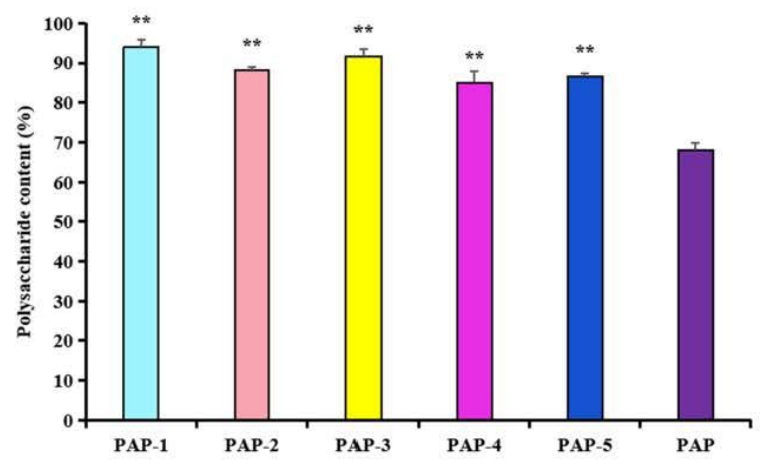

Figure 2. The elution curve of PAP was separated and purified by Cellulose DE-52 chromatography column (A) and Sephacryl S-200 high-resolution chromatography column (B-F) respectively; (G) Polysaccharide content of PAPs (means $\pm \mathrm{SD}, n=3)$. Bars with ${ }^{* *}$ indicates most significant difference with other groups $(p<0.01)$. 
A
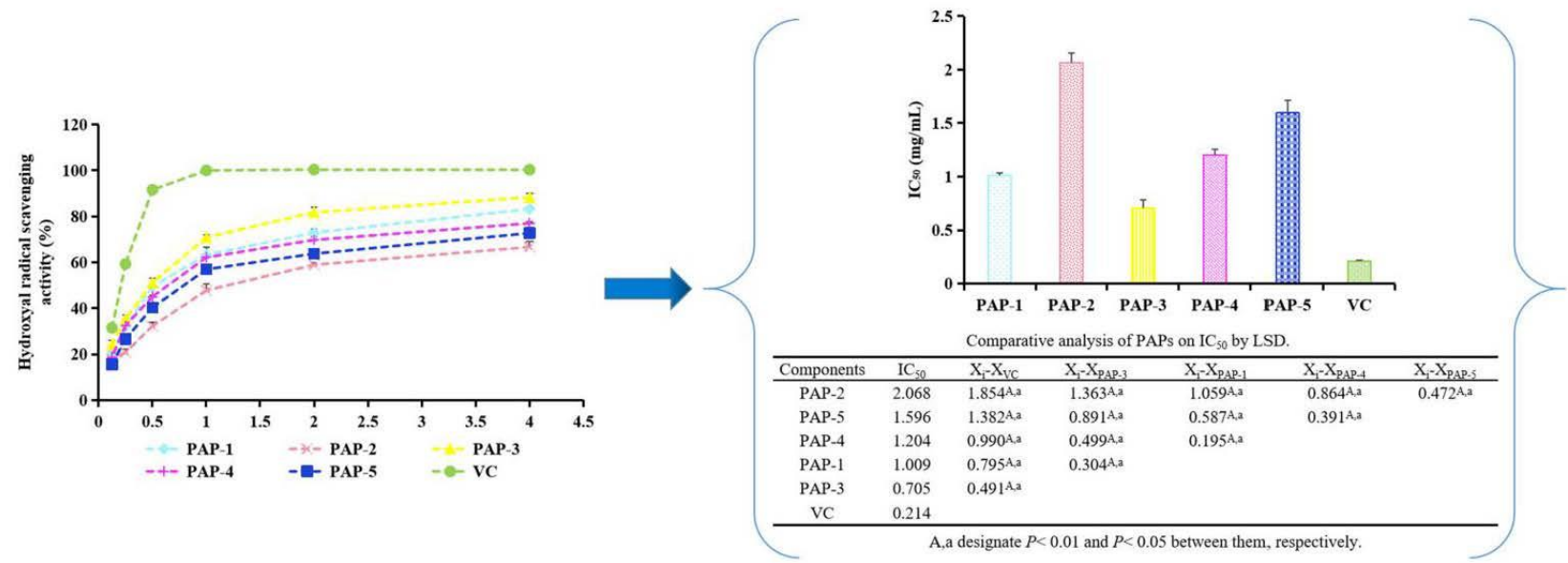

B
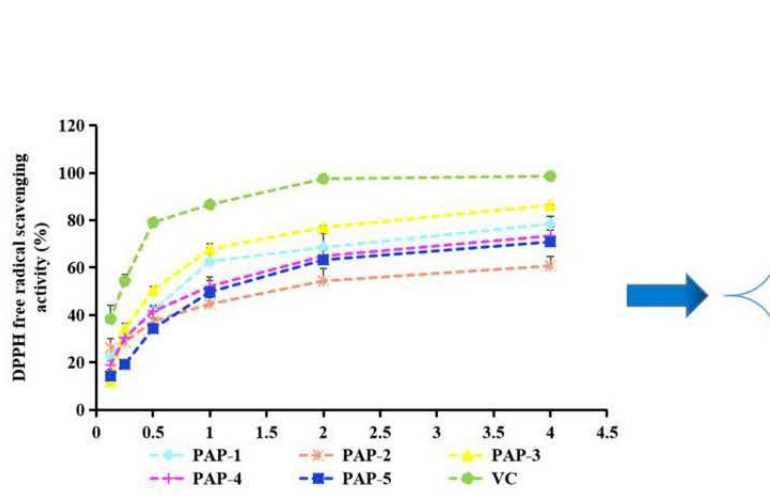

A designate $P<0.01$ and $P<0.05$ between them, respectively.

C
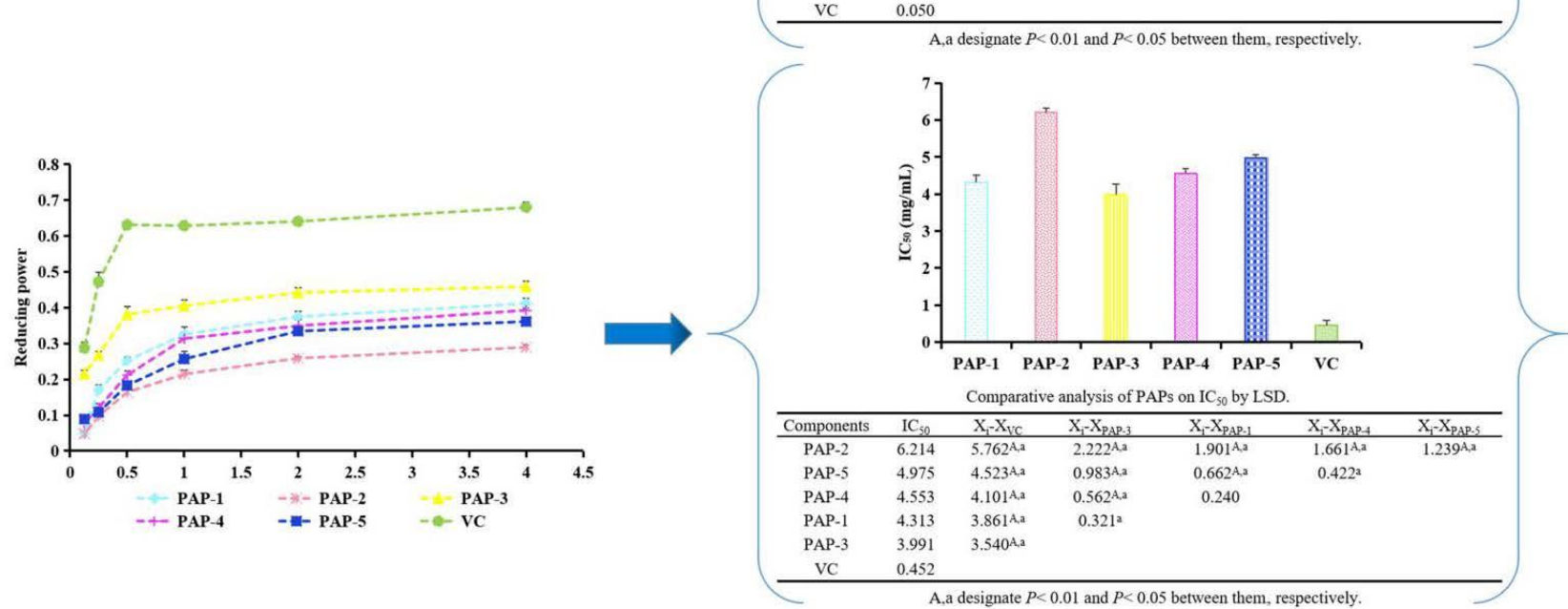

Figure 3. (A) Scavenging activity of PAPs on hydroxyl free radicals. (B) Scavenging activity of PAPs on DPPH free radicals. (C) Reducing power of PAPs. (means $\pm \mathrm{SD}, n=3$ ). "A, a" designate $p<0.05$ or $p<0.01$ between them.

\subsection{Structure Analysis of PAP-1}

\subsubsection{Molecular Weight}

From Figure 4A, the equation of the lgMw-RT calibration curve was $y=-0.206 x+12.862$ $\left(R^{2}=0.9919\right)$. The Mw of PAP- 1 was calculated by the formula to be $1.48 \times 10^{6} \mathrm{Da}$. 
A
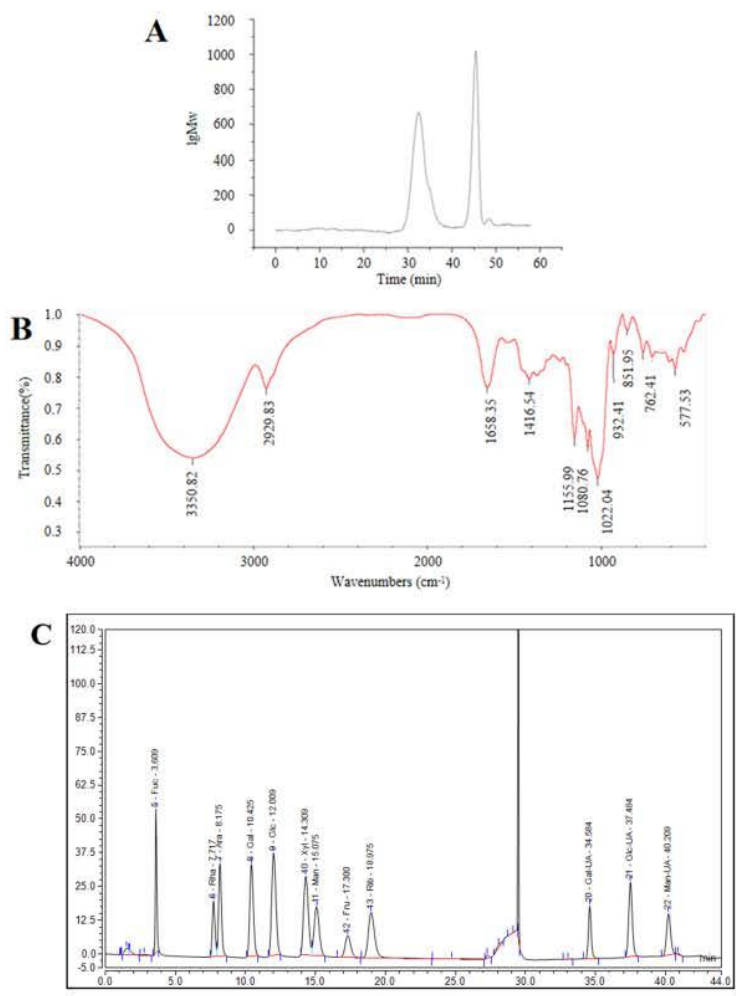

D

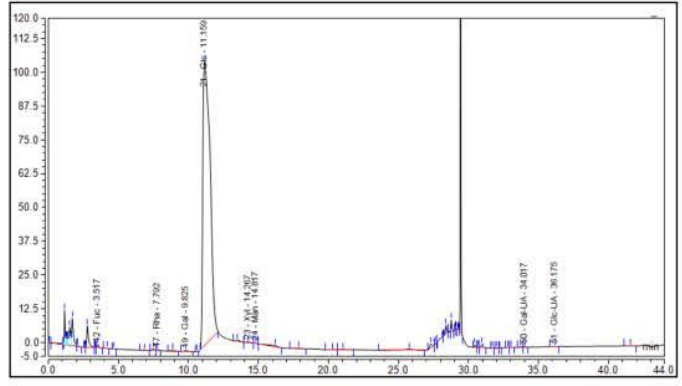

$\mathbf{E}$

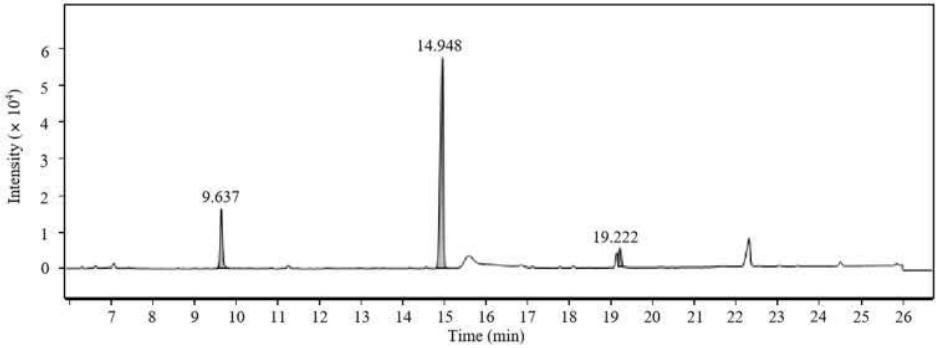

$\mathbf{F}$

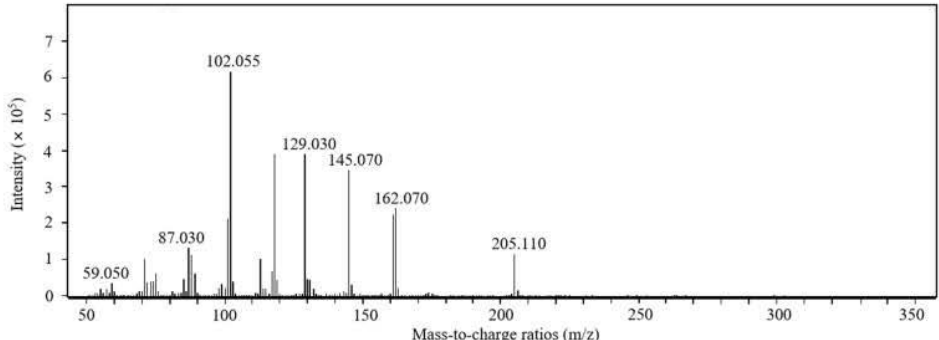

G

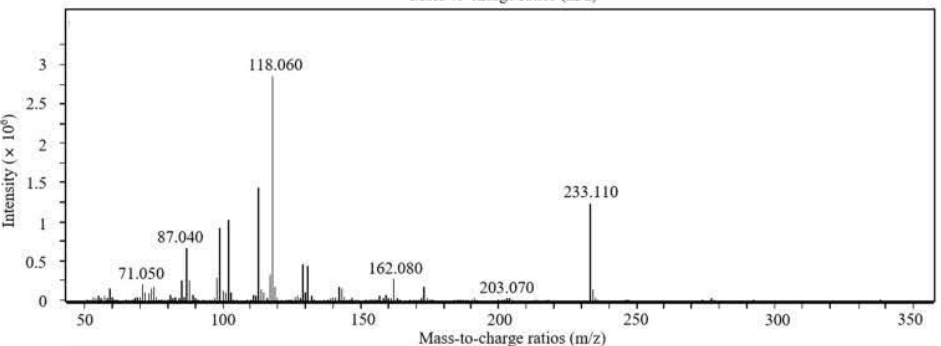

H

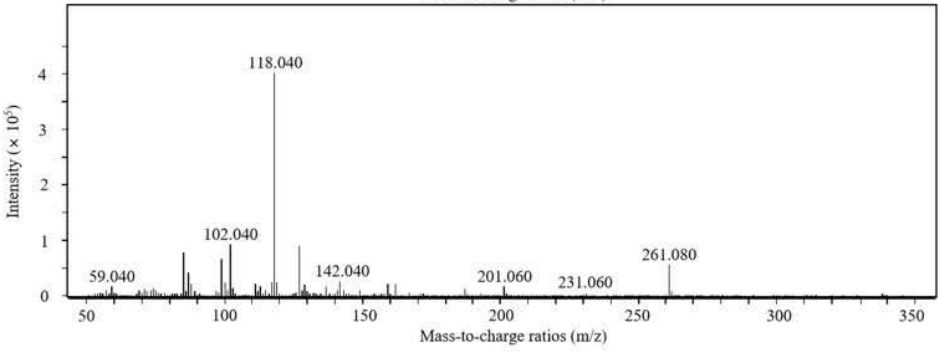

Figure 4. HPGPC chromatogram (A) and FT-IR spectrum (B) of PAP-1. Chromatogram of standard (C) and PAP-1 (D). The spectrum of PAP-1 by methylation analysis: (E) Spectrum of total ion flow of PAP-1; (F) Spectrum of t-Glc(p);

(G) Spectrum of 4-Glc(p); (H) Spectrum of 4,6-Glc(p).

\subsubsection{Specific Optical Rotation}

The specific rotation $[\alpha]^{20} \mathrm{D}$ of PAP- 1 at $20{ }^{\circ} \mathrm{C}$ was $+196.5^{\circ}\left(\mathrm{c}=0.4 \mathrm{mg} / \mathrm{mL}, \mathrm{H}_{2} \mathrm{O}\right)$. The higher positive value of optical rotation indicated that PAP-1 mainly exhibits $\alpha$ glycosidic bonding [41].

\subsubsection{FT-IR}

In Figure 4B, there was a strong absorption peak at $3350.82 \mathrm{~cm}^{-1}$, which was attributed to the stretching vibration of hydroxyl groups. The absorption peak produced by the stretching vibration of C-H appeared at $2929.83 \mathrm{~cm}^{-1}$. These two characteristic absorption peaks indicated the presence of polysaccharides in the sample [42]. The peak at $1658.35 \mathrm{~cm}^{-1}$ was the hydration vibration peak C-O of polysaccharides [43]. The peak at $1416.54 \mathrm{~cm}^{-1}$ was due to the bending vibration of $\mathrm{C}-\mathrm{H}$. Three peaks at 1155.99, 1080.76, and $1022.04 \mathrm{~cm}^{-1}$ indicated the presence of a pyranose ring and was caused by the C-O-C vibration. The peak of carbohydrate molecules, that is, the asymmetric ring stretching vibration of pyranose, appeared at $932.41 \mathrm{~cm}^{-1}$. The absorption peak at $851.95 \mathrm{~cm}^{-1}$ indicated that there were $\alpha$-glycosidic bonds and $\mathrm{C}-\mathrm{H} \alpha$-anomers. The peak at $762.41 \mathrm{~cm}^{-1}$ was due 
to the inclusion of $\mathrm{C}-\mathrm{O}-\mathrm{C}$ and was caused by the stretching vibration of the symmetric ring of D-glucopyranose [44]. In conclusion, PAP-1 is an $\alpha$-configured neutral polysaccharide with a pyranose ring.

\subsubsection{Analysis of Monosaccharide Composition}

The molar ratio of the monosaccharide composition of PAP-1 was: fucose:6-Deoxy-Lmannosehydrat:arabinose:galactose:glucose:xylose:mannose:galacturonic acid:glucuronic acid = 0.15:0.15:0.08:0.02:54.99:0.06:0.04:0.01:0.02 (Figure 4C,D). Chaiklahan et al. found that the content of rhamnose in PAP was the highest, but our results showed that the content of glucose was the highest in PAP-1, which may be due to the monosaccharide compositions of PAP being related to its place of origin [45].

\subsubsection{Periodate Oxidation and Smith Degradation}

After PAP-1 was oxidized by periodic acid, the consumption of periodic acid and the formation of formic acid were $1.02 \mathrm{mM}$ and $0.08 \mathrm{mM}$, respectively. The oxidized samples were subjected to smith degradation, and then the products were reduced. The products were mainly erythritol and a small amount of glycerol, which indicated that there were glucose residues linked by $(1 \rightarrow 4)$ glycosidic bonds in PAP-1.

\subsubsection{Methylation Analysis}

Three kinds of connection modes (t-Glc(p); 4-Glc(p); 4,6-Glc(p)) and three derivatives (1,5-di-O-acetyl-2,3,4,6-tetra-O-methyl glucitol; 1,4,5-tri-O-acetyl-2,3,6-tri-O-methyl glucitol; 1,4,5,6-tetra-O-acetyl-2,3-di-O-methyl glucitol) were obtained by methylation analysis of PAP-1 (Figure 4E-H).

\subsubsection{NMR}

The ${ }^{1} \mathrm{H}$ NMR spectrum signals of PAP-1 were mainly concentrated between 3.0 and $5.5 \mathrm{ppm}$. The proton signals of the sugar ring appeared between $83.2-4.0 \mathrm{ppm}$, and the signal peaks of the main terminal matrix were present at $\delta 5.31,5.26,5.15,4.89$, and $4.57 \mathrm{ppm}$ and were concentrated in the range of $4.3 \sim 5.5 \mathrm{ppm}$ (Figure 5A).

From Figure $5 \mathrm{~B}$, the signals in the ${ }^{13} \mathrm{C}$ NMR $\left(201 \mathrm{MHz}, \mathrm{D}_{2} \mathrm{O}\right)$ spectrum of PAP-1 were mainly concentrated between $60-120 \mathrm{ppm}$. By observing the carbon spectrum, it can be seen that the main anomeric carbon signal peaks were mainly located between $\delta 93$ and $105 \mathrm{ppm}$; they appeared at $\delta 101.33,101.05,99.88,97.01$, and 93.33 , separately. The main signal peaks between $60-80 \mathrm{ppm}$ appeared at $879.52,78.39,78.31,77.5,77.4,77.1,75.56$, 74.99, 74.56, 74.03, 74.02, 72.91, 72.86, 72.8, 72.53, 72.11, 71.94, 71.68, 70.69, 70.61, 68.46, $62.3,61.89$, and $61.67 \mathrm{ppm}$. These results, combined with monosaccharide composition analysis, showed that PAP-1 mainly contained glucose. According to the analysis of the DEPT135 NMR spectrum, the peaks at $61.67,62.3,61.89$, and $68.46 \mathrm{ppm}$ were inverted peaks, indicating that they were $\mathrm{C} 6$ chemical shifts.

The anomeric carbon signal was at $\delta 101.05$, and the corresponding anomeric hydrogen signal was 85.32 in the HQSC spectrum (Figure 5C). Through the HH-COSY spectrum (Figure 5D), the signals of H1-2 were at 5.32/3.55, H2-3 was 3.55/3.90 and H3-4 was at 3.90/3.58. We can infer that $\mathrm{H} 1, \mathrm{H} 2, \mathrm{H} 3$, and $\mathrm{H} 4$ corresponded to the peaks at $\delta 5.31,3.55$, 3.90 , and 3.58 , respectively. The TOCSY spectrum showed that the peak at $\delta 5.32$ correlated to the peaks at 3.58, 3.78, and 3.90, and H5 was 3.78 ppm (Figure 5E). The corresponding $\mathrm{C} 5$ appeared at 72.53 , the chemical shift of $\mathrm{C} 6$ was 861.95 , and the corresponding H6a was at $\delta 3.79$. Therefore, the signal should be attributed to the glycosidic bond $\rightarrow 4$ )- $\alpha$-Glcp$(1 \rightarrow[46]$.

In the HMBC spectrum (Figure 5F), according to the one-dimensional and two-dimensional NMR spectrum, we attributed the glycosidic bond signal of PAP-1. The anomeric hydrogen of glycosidic bond $\rightarrow 4)-\alpha$-D-Glcp- $(1 \rightarrow)$ had a correlation signal peak with its own C4, and the anomeric carbon had a single correlation peak with its own $\mathrm{H} 4$, which indicated that there was a linkage mode of $\rightarrow 4)-\alpha$-D-glcp-( $1 \rightarrow 4)$ - $\alpha$-D-glcp- $(1 \rightarrow)$. 
A

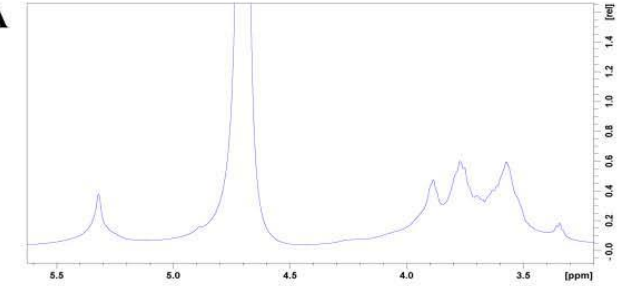

C

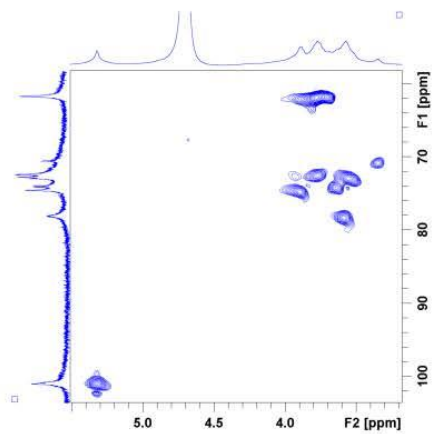

$\mathbf{E}$

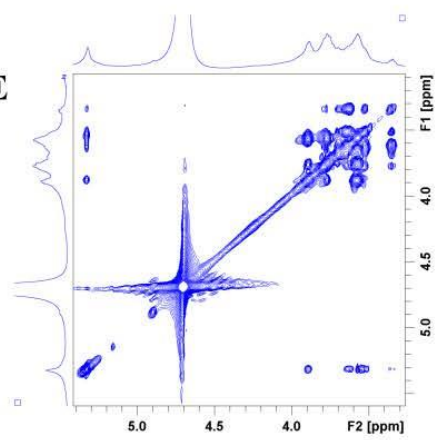

G

$\alpha-D-G \mid c p-\left(1 \rightarrow[4)-\alpha-D-G \mid c p-(1]_{n} \rightarrow\right.$

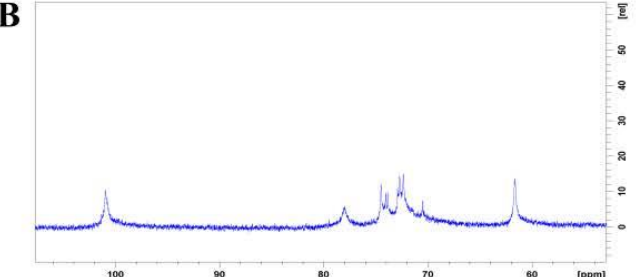

D
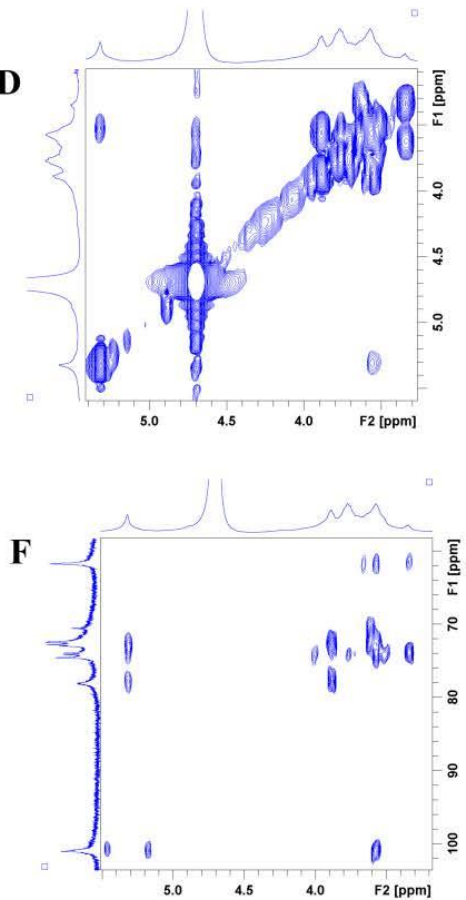

H

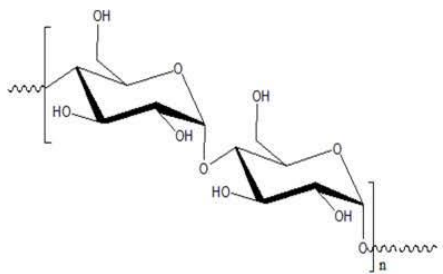

Figure 5. NMR spectrum and structure of PAP-1. (A) ${ }^{1} \mathrm{H}$ NMR spectrum; (B) ${ }^{13} \mathrm{C}$ NMR spectrum; (C) HH-COSY spectrum; (D) HSQC spectrum; (E) HMBC spectrum; (F) TOCSY spectrum; (G) Bonding structures of PAP-1; (H) Structural formula of PAP-1.

In summary, we can infer that the main glycosidic bond structure of the polysaccharide was a $\rightarrow 4)$ - $\alpha$-D-Glcp- $(1 \rightarrow$ glycosidic bond. The bonding structures and structural formula of PAP-1 are shown in Figure 5G,H, respectively. Chen et al. showed that the monosaccharides of PAP were mainly composed of rhamnose, fucose, arabinose, xylose, mannose, and glucose with the molar ratio of 3.42:0.76:0.34:0.53:0.43:0.59 [5]. The results of Pr et al. showed that PAP contained a relatively large proportion of galactose [9]. Ma et al. found that PAP was mainly composed of rhamnose, glucose, and galactose [6]. Similarly, Chaiklahan et al. found that the content of rhamnose in PAP was the highest [45]. Li et al. showed that PAP-1 was mainly composed of glucose, which was similar to our results. The difference was that its structure has a C-6 branched by an $\alpha$-D-Glcp, and its molecular weight was 93.856 KDa. In addition, they obtained spirulina from Fujian Shenliu Health Food Co. (Fujian, China) by alkali liquor extraction, which was different from our purchasing place and extraction method [47]. Perhaps the structures of PAP obtained by different 
extraction methods in different regions may be similar or different, which were helpful to lay a foundation for further study of its mechanism of action.

\subsection{The Effect of PAP-1 on the Activity of RAW264.7 Cells}

PAP-1 could significantly increase cell activity in the range of $25 \mu \mathrm{g} / \mathrm{mL}-400 \mu \mathrm{g} / \mathrm{mL}$ within $8-48 \mathrm{~h}$, while PAP-1 at concentrations of $800 \mu \mathrm{g} / \mathrm{mL}$ and $1600 \mu \mathrm{g} / \mathrm{mL}$ significantly decreased the activity of cells at $48 \mathrm{~h}(p<0.01)$ (Figure 6A). Perhaps the concentrations of PAP-1 at $800 \mu \mathrm{g} / \mathrm{mL}$ and $1600 \mu \mathrm{g} / \mathrm{mL}$ were a little high, which caused toxic effects on RAW264.7 cells. Most studies have shown that the polysaccharide components isolated and purified from plant polysaccharides can promote cell proliferation in a suitable concentration range (Excessively low concentration of plant polysaccharide may not significantly improve cell activity, while excessive concentration may cause toxicity to cells and inhibit cell proliferation) $[10,48,49]$. This study was consistent with the above research results. Therefore, PAP-1 in the concentration range of $25-400 \mu \mathrm{g} / \mathrm{mL}$ was used for subsequent experiments.

A

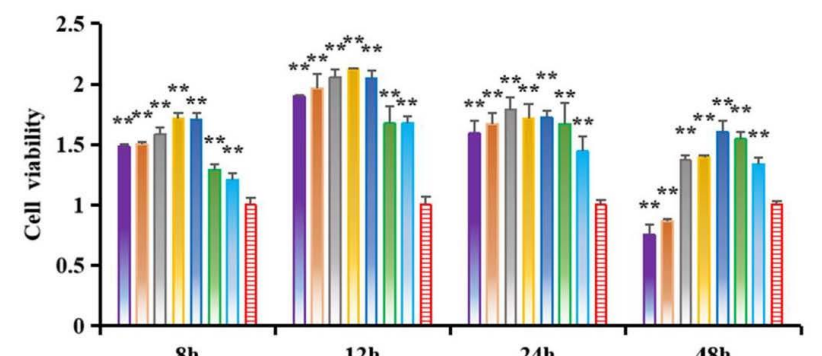

8h

12h

48h

$\square$ PAP-1(1600) $=$ PAP-1(800) $\square$ PAP-1(400) $\square$ PAP-1(200)

$\square$ PAP-1(100) $\square$ PAP-1(50) $\square$ PAP-1(25) 目 Cell

B

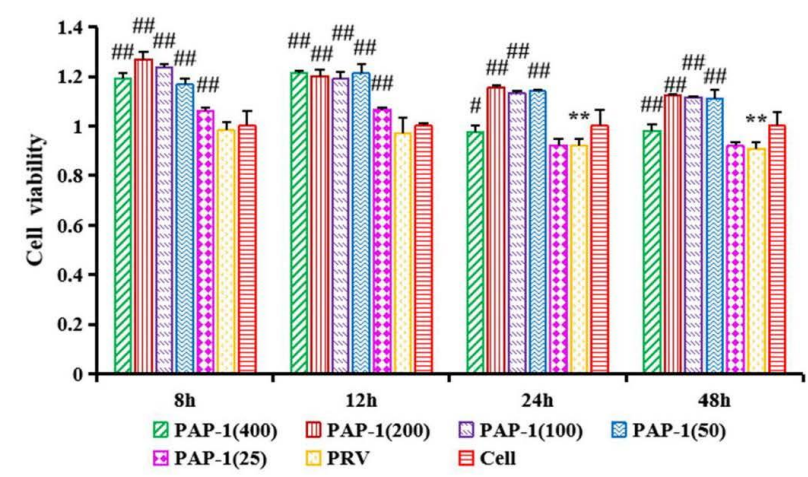

C

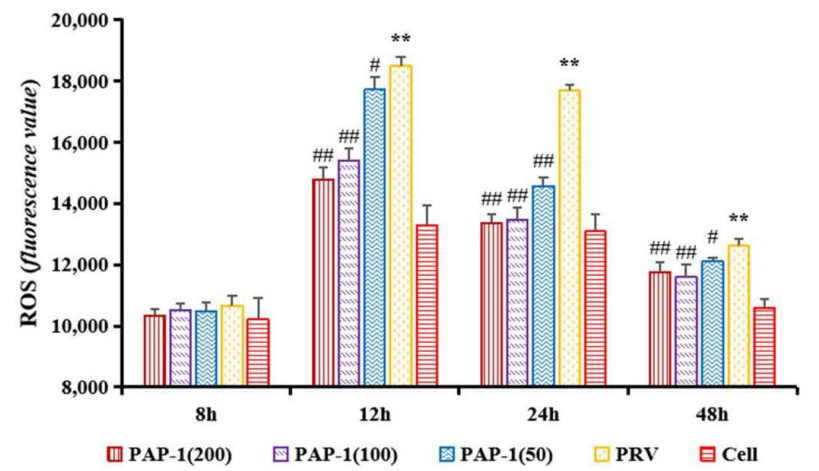

Figure 6. The effect of PAP-1 on the activity of RAW264.7 cells (A). The regulation of PAP-1 on the activity (B) and ROS level (C) in PRV-infected RAW264.7 cells. (means \pm SD, $n=4$ ). Bars with \# indicate a significant difference between the PRV group, respectively $(p<0.05) .{ }^{* *}$ and \#\# show the most significant differences with cell group and PRV group, respectively $(p<0.01)$. 


\subsection{The Effect of PAP-1 on the Activity of PRV-Infected RAW264.7 Cells}

Macrophages are ancient and conservative immune cells that play a key role in host defense and innate immune responses. They can not only initiate the innate immune response but also help to fight infections and inflammation [50]. Adverse stimulation can decrease the activity of macrophages, while plant polysaccharides can increase cell activity caused by harmful stimulation [51]. In this study, the cell activity of the PRV group was highly significantly lower than that of the cell group at $24 \mathrm{~h}$ and $48 \mathrm{~h}(p<0.01)$. Compared with the PRV group, PAP-1 in the range of 50-400 $\mu \mathrm{g} / \mathrm{mL}$ incubated for $24 \mathrm{~h}$ and $48 \mathrm{~h}$ significantly increased cell activity $(p<0.05$ or $p<0.01)$. Among them, PAP-1 groups $(50-200 \mu \mathrm{g} / \mathrm{mL})$ have a better effect, so they were selected for subsequent experiments (Figure 6B).

\subsection{The Effect of PAP-1 on Antioxidant Capacity in PRV-Infected RAW264.7 Cells}

Oxidative stress originates from the imbalance between the oxidant produced by ROS and the endogenous antioxidant. Endogenous and exogenous oxidants are related to disease development [52]. The main component involved in oxidative stress is ROS, which is characterized by oxygen-containing reactive chemicals, such as superoxide anion $\left(\mathrm{O}_{2}{ }^{\bullet-}\right)$, hydrogen peroxide $\left(\mathrm{H}_{2} \mathrm{O}_{2}\right)$, hydroxyl radical $\left({ }^{\bullet} \mathrm{OH}\right)$ and so on. Excessive ROS levels caused by adverse stimulation will cause lipid peroxidation and then produce MDA [53]. MPO can mediate oxidative stress by promoting the production of ROS and reactive nitrogen (RNS) [54]. Xanthine oxidase (XOD) is a homodimer with a molecular weight of $290 \mathrm{kDa}$, which widely exists in various tissues from bacteria to humans and mammals. XOD uses dioxygen as its substrate to produce $\mathrm{O}_{2}{ }^{--}$and $\mathrm{H}_{2} \mathrm{O}_{2}$ [55]. SOD is responsible for catalyzing the conversion of $\mathrm{O}_{2}{ }^{\bullet-}$ into $\mathrm{H}_{2} \mathrm{O}_{2}$, and then GSH-Px and CAT convert $\mathrm{H}_{2} \mathrm{O}_{2}$ into $\mathrm{H}_{2} \mathrm{O}$ [56]. At present, many studies have shown that natural plans can improve the antioxidant activity of hosts and are potent antioxidants, which provide a basis for the development and utilization of antioxidant plants. Natural compounds can alleviate cerebral ischemia injury by targeting the activity of MPO to alleviate oxidative stress [54]. Passiflflora edulis rinds can eliminate the ROS generated by stimulated polymorphonuclear neutrophils production and inhibit MPO activity to decrease oxidative stress [57]. Taking the XOD inhibitor from plants may be a promising method to prevent microbial infection, inflammation, hypertension, and ischemia/reperfusion injury caused by excessive production of $\mathrm{O}_{2}{ }^{\bullet-}$ [55]. Okra Polysaccharide can reduce ROS and MDA, and increase SOD, GSH-Px, and CAT in the liver of mouse type 2 diabetes mellitus model, that is, it can reduce blood sugar by relieving oxidative stress [58]. The treatment of momordica charantia polysaccharides decreased the level of MDA and increased the activities of SOD and CAT in the hippocampus of Kainic acid-induced epileptic rats, and reduced the neuronal damage in the brain induced by kainic acid, which played a neuroprotective role [59]. From Figure 6C, the ROS level in the PRV group was significantly higher than that in the cell group and the levels of ROS in the PAP-1 groups were significantly lower than those in the PRV group at $12-48 \mathrm{~h}(p<0.05$ or $p<0.01)$. As shown in Figure 7A-F, MDA level, and MPO and XOD activities were significantly increased after PRV-infected RAW264.7 cells, while SOD, CAT, and GSH-Px activities were extremely significantly decreased $(p<0.01)$. PAP-1 $(50 \mu \mathrm{g} / \mathrm{mL})$ could significantly reduce MDA level, MPO activity, and increase SOD and CAT activities ( $p<0.05$ or $p<0.01) .100 \mu \mathrm{g} / \mathrm{mL}$ and $200 \mu \mathrm{g} / \mathrm{mL}$ of PAP-1 could significantly reduce the level of MDA, the activities of MPO and XOD, and increase the activities of SOD, CAT, and GSH-Px $(p<0.01)$. The expression levels of MPO and XOD mRNA increased significantly $(p<0.01)$, while the mRNA expression levels of SOD and GSH-Px decreased significantly after PRV infected RAW264.7 cells $(p<0.05$ or $p<0.01$ ). Different concentrations of PAP-1 can significantly reduce the expression levels of MPO and XOD mRNA, and significantly increase the mRNA expression levels of SOD and GSH-Px $(p<0.01)$ (Figure 7G). The results of this study are also consistent with those of the above studies. The results indicated that PAP- 1 with different concentrations could protect RAW264.7 cells by improving the antioxidant capacity of PRV-infected RAW264.7 
cells. However, the molecular mechanism by which PAP-1 acts on PRV-infected RAW264.7 cells needs further study.

A

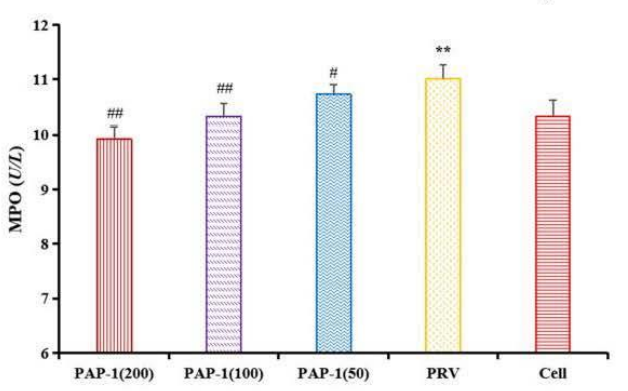

C

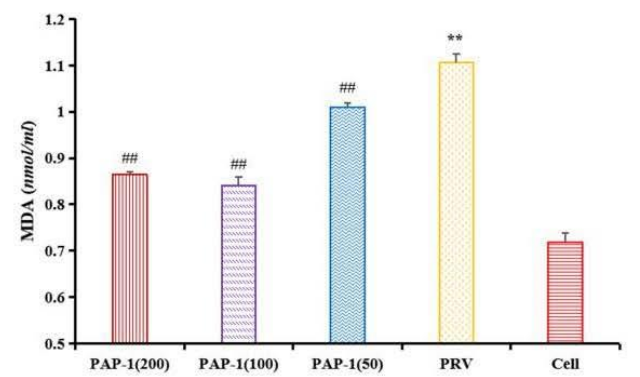

$\mathbf{E}$

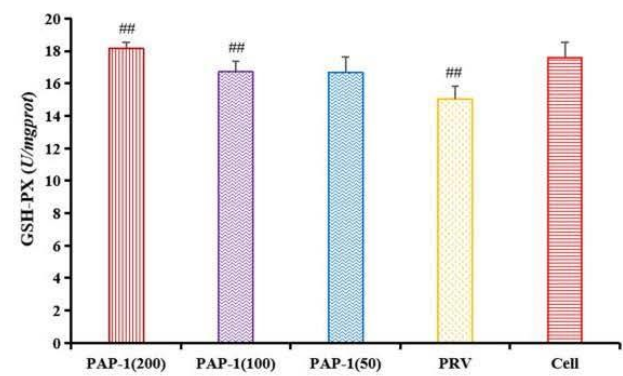

B

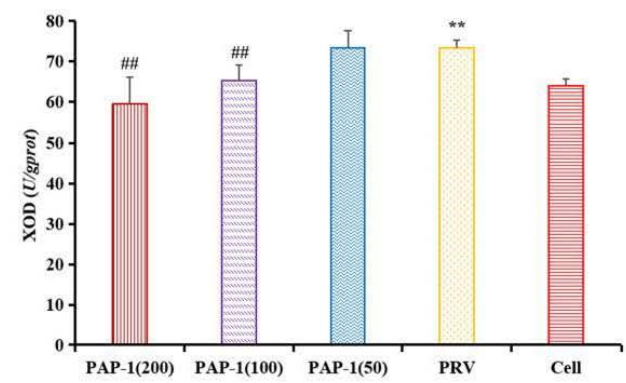

D

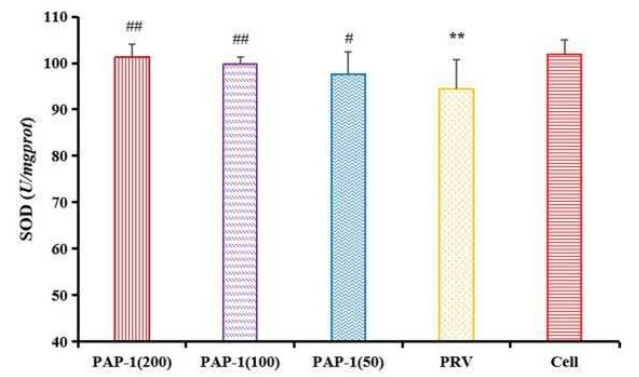

$\mathbf{F}$

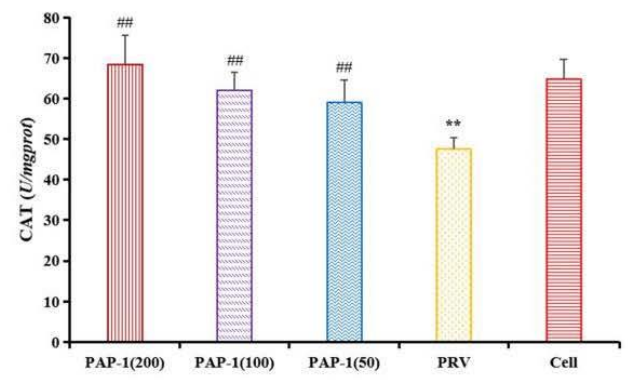

G

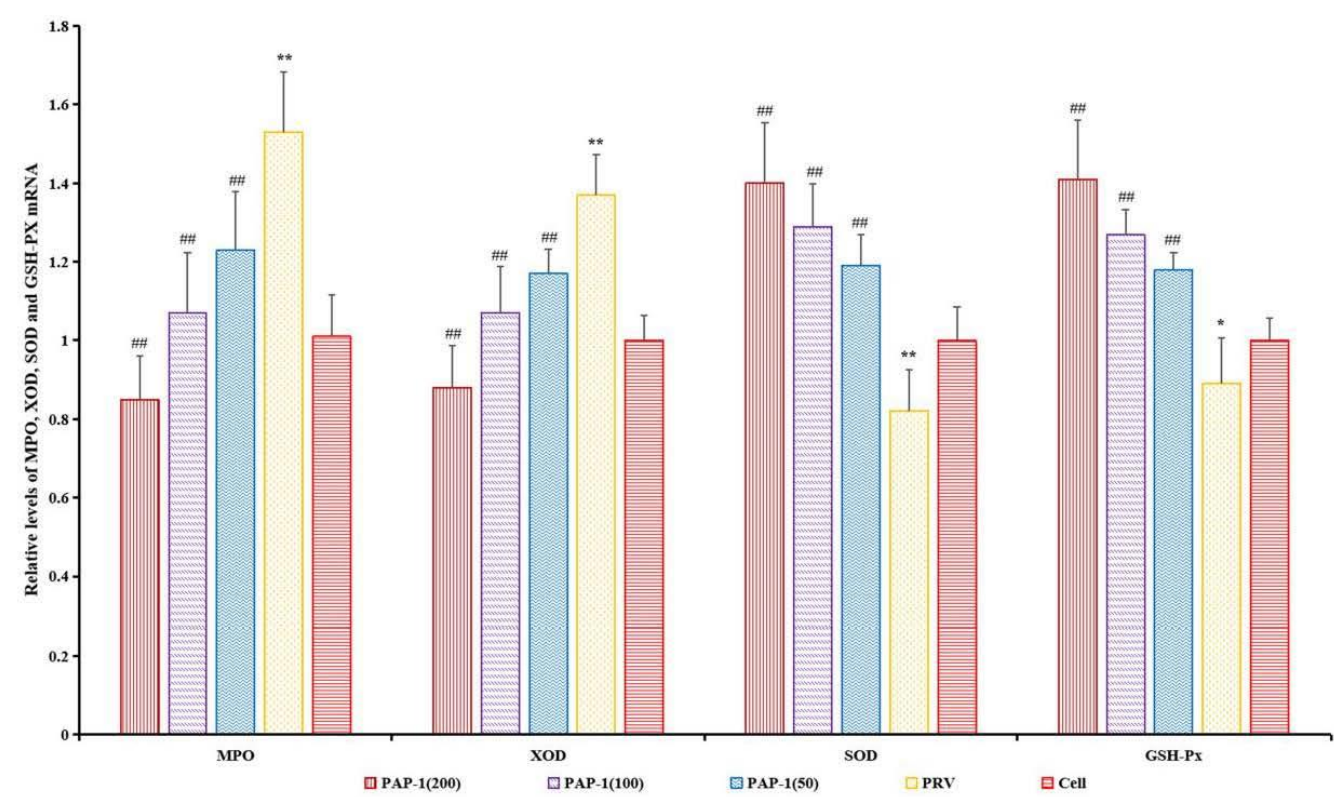

Figure 7. The effect of PAP-1 on the antioxidant activity of PRV-infected RAW264.7 cells. (A) The activity of MPO; (B) The activity of XOD; (C) The level of MDA; (D) The activity of SOD; (E) The activity of GSH-Px; (F) The activity of CAT; (G) Relative levels of MPO, XOD, SOD, and GSH-Px mRNA. (means \pm SD, $n=9$ ). Bars with * and \# indicate a significant difference between the cell group and the PRV group $(p<0.05)$. ** and \#\# show the most significant differences with the cell group and PRV group, respectively $(p<0.01)$. 


\subsection{The Effect of PAP-1 on the Network of CircRNA-miRNA-mRNA in PRV-Infected RAW264.7 Cells}

More and more evidence show that circRNA is closely related to virus infection, and it may play an important role in the pathogenesis and diagnosis of diseases through miRNA. CircRNA-miRNA-mRNA, a regulatory network, has also become an important direction of Chinese herbal medicine regulation. There are 151 circRNAs, 56 miRNAs, and 341 mRNAs differentially expressed in Orf virus-infected goatskin fibroblast cells [60]. The brains of mice infected with Rabies virus were sequenced, and the constructed circRNA-miRNAmRNA network was composed of 25 differentially expressed circRNAs, 29 miRNAs, and 264 mRNAs [61]. In this study, there were 17 differentially expressed circRNAs, 117 miRNAs, and 2113 mRNAs between $C$ group and $C V$ group (Figure $8 \mathrm{~A}-\mathrm{C})(p<0.05$, FC > 1.5). There are 13 differentially expressed circRNAs, 90 miRNAs, and 175 mRNAs between the CV group and the CVM group (Figure 8D-F) $(p<0.05$, FC $>1.5)$. Heat map generated by hierarchical clustering analysis of differentially expressed circRNA (Figure 8G,J), miRNA (Figure $8 \mathrm{H}, \mathrm{K}$ ), and mRNA (Figure 8I,L) showed that all samples were clustered into cell groups (C1, C2, C3), PRV group (CV1, CV2, CV3), and PAP-1 group (CVM1, CVM2, CVM3). The results indicated that PRV-infected RAW264.7 cells and PAP-1 acting on PRV-infected RAW264.7 cells caused the differential expression of circRNA, miRNA, and mRNA. To further analyze the regulatory roles among circRNA, miRNA, and mRNA, Cytoscape 3.7.1 software was used to construct a circRNA-miRNA-mRNA network diagram (Figure 9). Generally, the expression correlation between ceRNAs is negatively correlated, that is, circRNA can down-regulate the expression of target miRNAs, and miRNAs can down-regulate mRNA expression. Therefore, the regulatory effect of PAP-1 on PRV-infected RAW264.7 cells was screened based on the expression correlation of circRNA, miRNA and mRNA. Among them, 10 circRNAs, 30 miRNAs, and 71 mRNAs were involved in network regulation. Compared with the $\mathrm{CV}$ group, the mRNA expression levels of Igf1, Gclm, Sqstm1, and Slc7a11 genes related to antioxidant activities in the CVM group were significantly increased. The results showed that PRV-infected RAV264.7 cells caused a change in the regulation of the circRNA-miRNA-mRNA network, and PAP-1 acting on PRV-infected RAW264.7 cells may improve antioxidant activity by regulating the circRNA-miRNA-mRNA network.

To reveal the potential functions of differentially expressed circRNA, we used the Gene Ontology website and Innovative Path Analysis software to enrich the functions and signal pathways of circRNA and miRNA-targeted mRNA. Gene Ontology enrichment analysis includes molecular function, cellular component, biological process. The differentially expressed mRNAs screened from C Group and CV Group (Figure 10A-C) or CV Group and CVM Group (Figure 10D-F) were analyzed for Gene Ontology function enrichment by David database. In the molecular function of CV Group and CVM Group, genes are mainly enriched in peroxidase activity, antioxidant activity, and oxidoreductase activity acting on peroxide as acceptor, etc. Enrichment and screening of KEGG pathway in $\mathrm{C}$ group and $\mathrm{CV}$ group resulted in 315 signaling pathways, involving osteogenic class differentiation, c-type lectin receptor signaling pathway, MAPK signaling pathway, Viral carcinogenesis, TNF signaling pathway, herpes simplex infection, nod-like receptor signaling pathway, microRNAs in cancer, Malaria et al. (Figure 11A-D). 171 signal pathways were obtained by enrichment and screening of the KEGG pathway in the CV Group and the CVM Group, which mainly involved systemic lupus erythematosus, alcoholism, necroposis, viral carcinogenesis, fluid shear stress and atheroslerosis, transcriptional misregulation in cancers, and others signaling pathways (Figure 11E-H). Chicken infected with ALV-J also caused the differential expression of circRNA, in which circRNA_3079 and predicted target genes were mostly concentrated in immune or tumor-related signaling pathways, such as p53 signaling pathway, JAK-stat signaling pathway, nod-like receptor signaling pathway, and other signaling pathways [62]. In addition, total saponins from the leaves of Panax notoginseng saponins can regulate chronic unpredictable mild stress. In the model group, the ventral median prefrontal cortex and hippocampus of C57BL male mice expressed 
a large amount of circRNA, which may be an important mediator of the antidepressant effect of Panax notoginseng saponins [63]. The abnormal expression of circRNA may lead to defective or abnormal cell functions, resulting in a variety of human diseases. At the same time, circRNA can be used as a good biomarker because of its structural stability and high tissue specificity $[64,65]$, so it may become a more accurate and effective target for the diagnosis and treatment of diseases in the future.

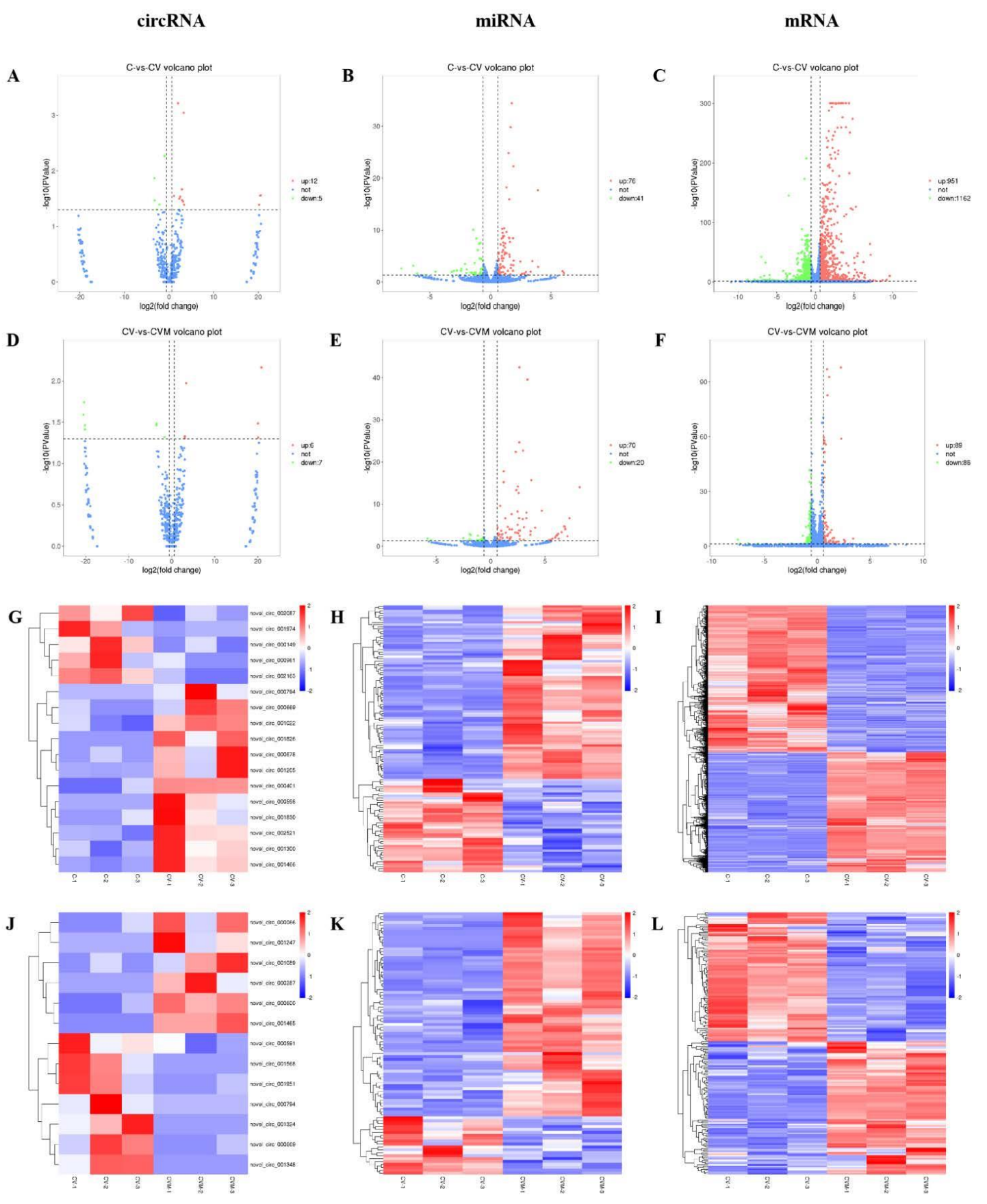

Figure 8. Volcano map and cluster heat map of circRNA, miRNA, and mRNA expression. 17 differentially expressed circRNAs, 117 miRNAs, and 2113 mRNAs between $C$ group and CV group $(\mathbf{A}-\mathbf{C})(p<0.05, \mathrm{FC}>1.5)$. There are 13 differentially expressed circRNAs, 90 miRNAs, and 175 mRNAs between the CV group and the CVM group (D-F) ( $p<0.05$, FC > 1.5). Heat map generated by hierarchical clustering analysis of differentially expressed circRNA $(\mathbf{G}, \mathbf{J})$, miRNA (H,K), and mRNA $(\mathbf{I}, \mathbf{L})$. 


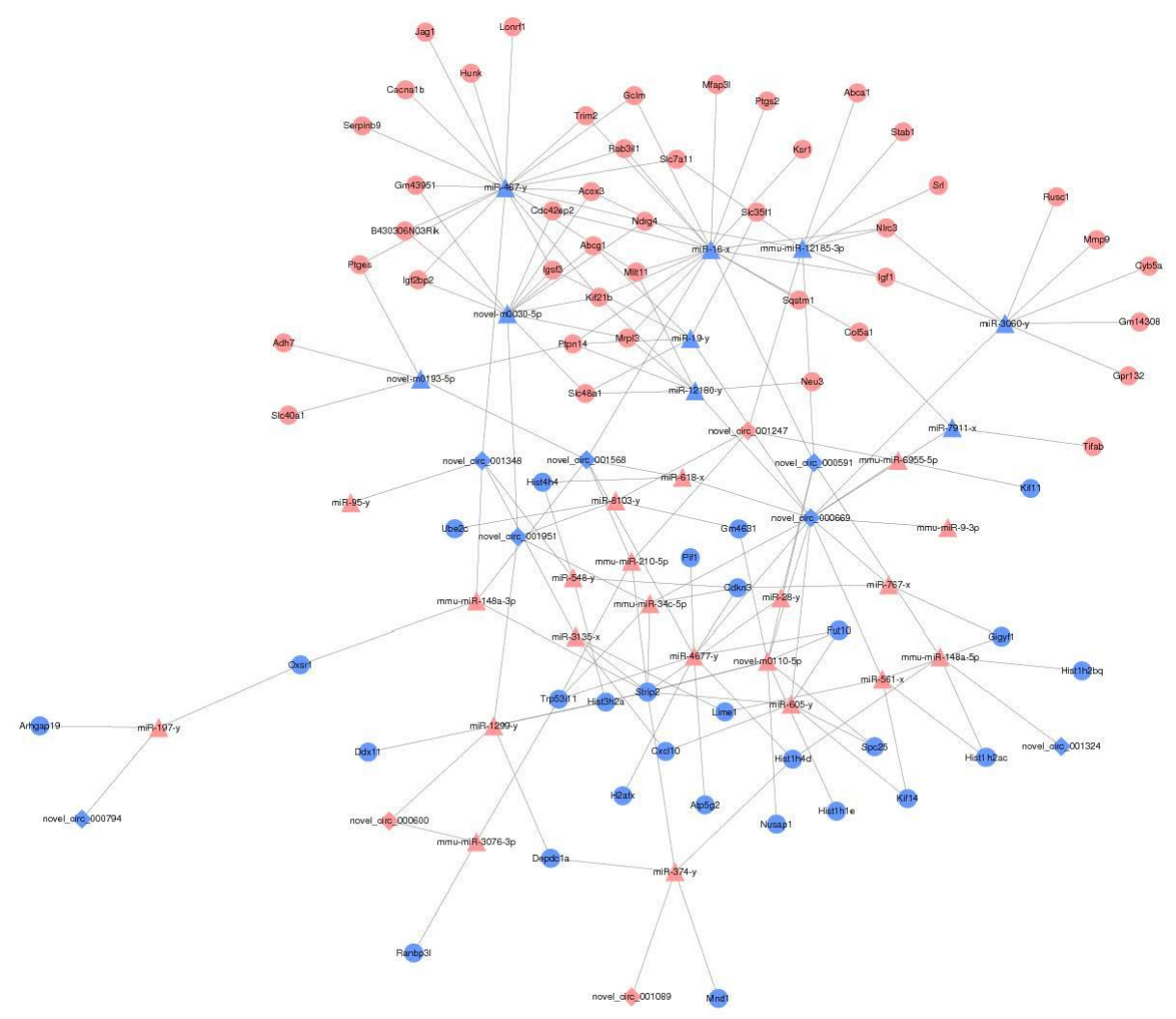

Figure 9. The regulation network of PAP-1 on circRNA-miRNA-mRNA in PRV-infected RAW264.7 cells. The up-regulated mRNA was represented as a red circle, while the down-regulated mRNA was represented as a blue circle. The up-regulated circRNA was represented by a red diamond, while the down-regulated circRNA was represented by a blue diamond. The up-regulated miRNA is represented by a red triangle, while the down-regulated miRNA is represented by a blue triangle. Sequence targeting relationships between miRNA and other RNA analyses are shown in black lines.
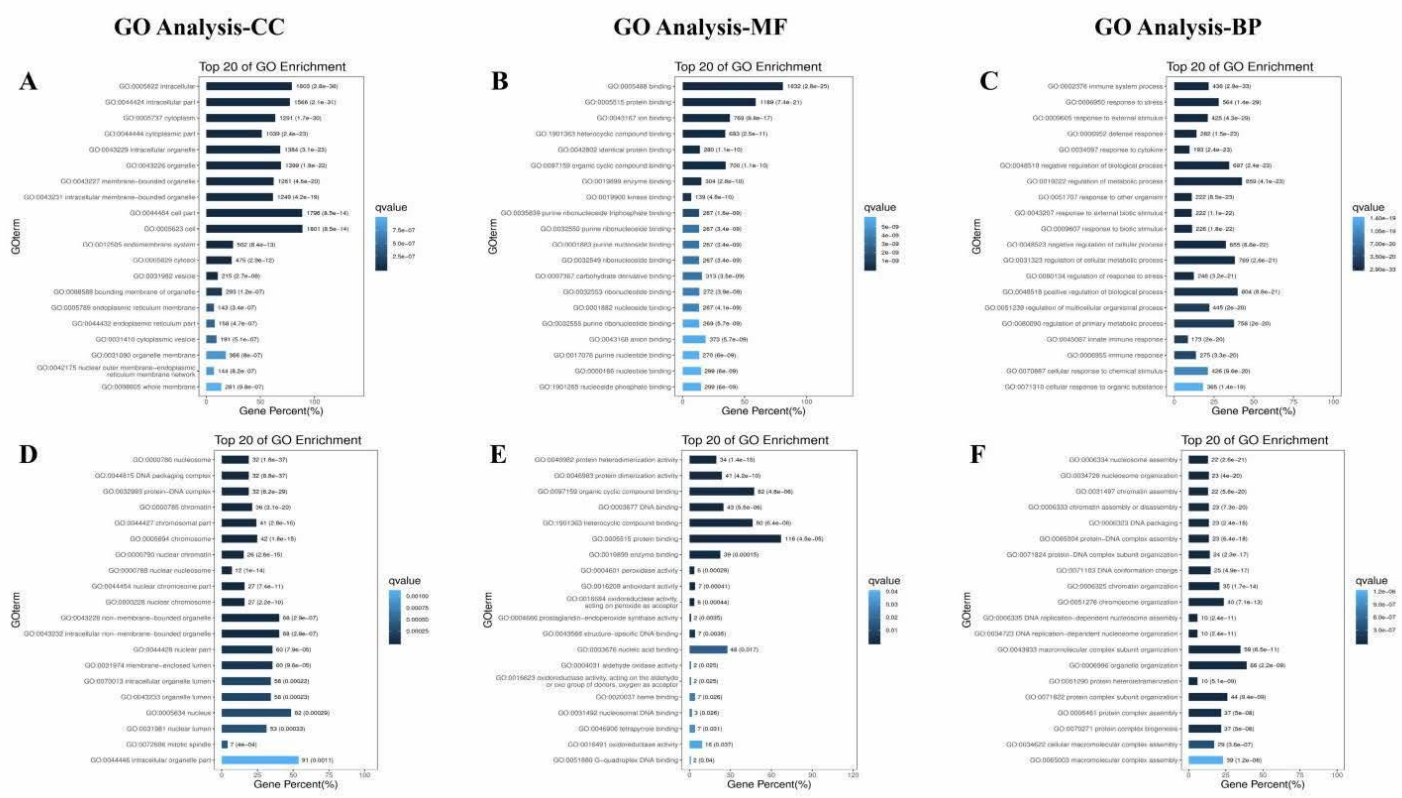

Figure 10. Gene Ontology term analysis of differentially expressed mRNA. C group and CV group: Gene Ontology annotation of mRNA in cellular components (A), molecular functions (B), and biological process (C). CV group and CVM group: Gene Ontology annotation of mRNA in cellular components (D), molecular functions (E), and biological process (F). GO, Gene Ontology; CC, cellular component; MF, molecular function; BP, biological process. 
A

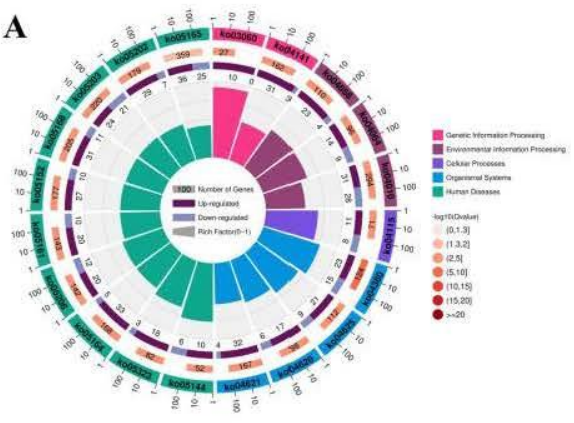

E

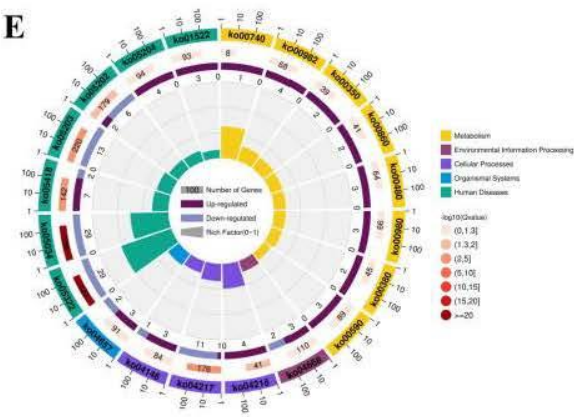

B

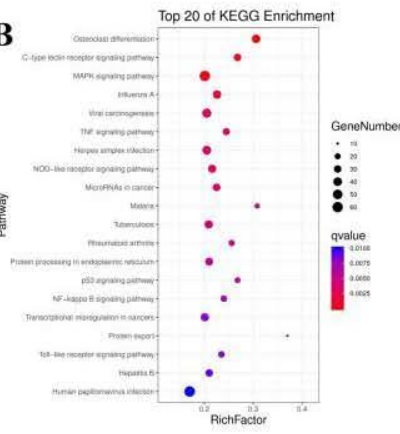

F

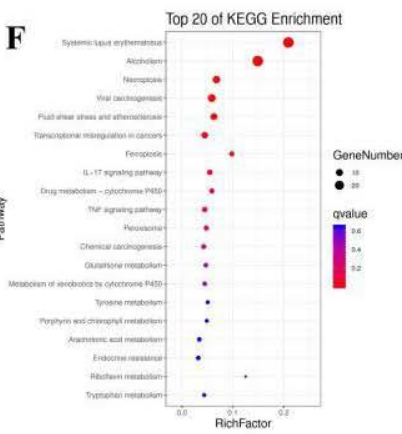

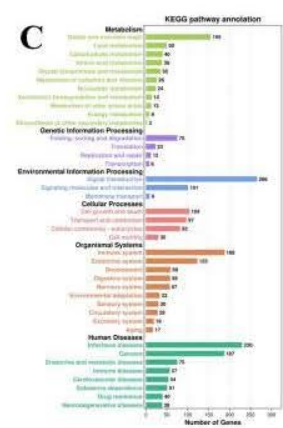
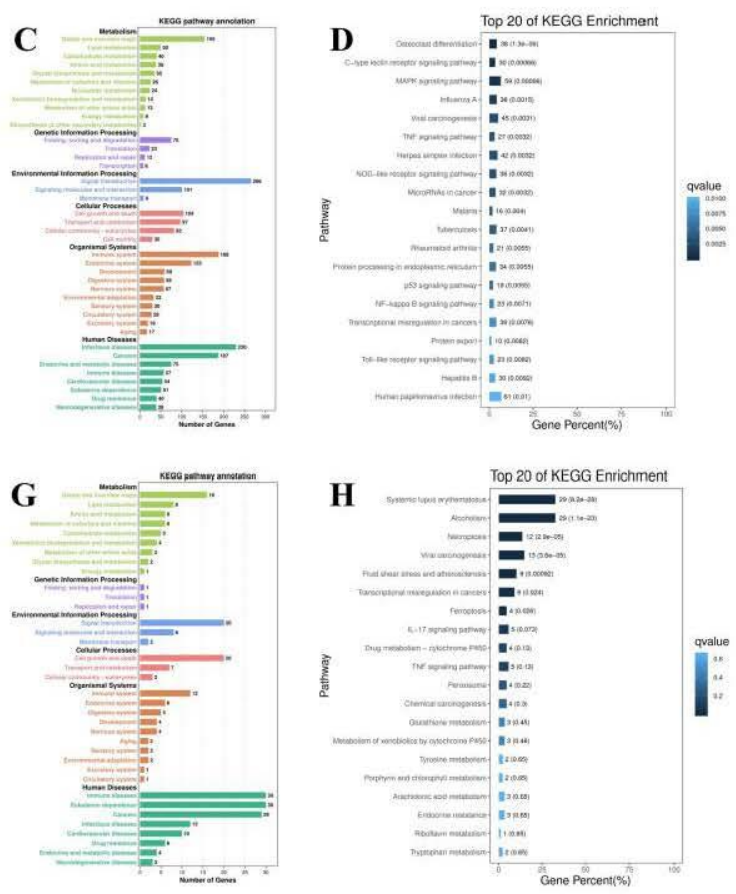

Figure 11. Ko term analysis of differentially expressed mRNA. Enrichment and screening of KEGG pathway in C group and CV group re-sulted in 315 signaling pathways, involving osteogenic class differentiation, c-type lectin re-ceptor signaling pathway, MAPK signaling pathway, Viral carcinogenesis, TNF signal-ing pathway, herpes simplex infection, nod-like receptor signaling pathway, microRNAs in cancer, Malaria et al. (A-D). 171 signal path-ways were obtained by enrich-ment and screening of the KEGG pathway in the CV Group and the CVM Group, which mainly involved systemic lupus erythematosus, alcoholism, necroposis, viral carcino-genesis, fluid shear stress and atheroslerosis, transcriptional misregulation in cancers, and others signaling pathways (E-H).

In conclusion, ceRNA-seq showed that PAP-1 increased the expression of antioxidationrelated genes in PRV-infected RAW264.7 cells by regulating the circRNA-miRNA-mRNA network, and caused changes in antioxidation-related signaling pathways. This study can provide a research basis for circRNA-miRNA-mRNA as a drug target to improve the antioxidant capacity of virus-infected cells.

\section{Conclusions}

PAP obtained from the enzyme-assisted hot water extraction method was isolated and purified, and the structure of PAP-1 was deeply studied. The main glycosidic bond structure of PAP-1 was $\rightarrow 4)$ - $\alpha$-D-Glcp- $(1 \rightarrow$. PAP-1 could increase the antioxidant capacity of PRVinfected RAW264.7 cells by regulating oxidation and antioxidant factors (MDA, MPO, XOD, SOD, GSH-Px, and CAT). In addition, the circRNA-miRNA-mRNA regulatory network was constructed, and the biological functions and regulatory pathways of differentially expressed mRNA in PRV-infected RAW264.7 cells incubated with PAP-1 were analyzed. We found that PAP-1 may be increased the antioxidant activity of PRV-infected RAW264.7 cells by regulating circRNA-miRNA-mRNA networks and antioxidation-related signaling pathways. This study can lay a certain experimental foundation and open up a new idea for elucidating the activity of PAP-1 from the structure.

Author Contributions: Conceptualization, M.-X.C. and T.-J.H.; Data curation, M.-X.C., X.-R.W., Q.C., and L.J.; Formal analysis, X.-D.X., X.-R.W., W.-Y.H., and Q.C.; Funding acquisition, T.-J.H.; Investigation, M.-X.C., X.-D.X., L.J., and M.-L.Y.; Methodology, W.-Y.H. and Y.Z.; Project administration, Y.-Y.W. and T.-J.H.; Supervision, M.-L.Y.; Visualization, Y.Z. and Y.-Y.W.; Writing and original draft, M.-X.C.; Writing, review and editing, T.-J.H. All authors have read and agreed to the published version of the manuscript. 
Funding: This research was financially supported by the National Natural Science Foundation of China [grant number 31960715] and Innovation Project of Guangxi Graduate Education [grant number YCBZ2020004].

Institutional Review Board Statement: Not applicable.

Informed Consent Statement: Not applicable.

Data Availability Statement: Data is contained within the article.

Conflicts of Interest: The authors declare no conflict of interest.

\section{References}

1. Wang, B.Y.; Liu, Q.; Huang, Y.H.; Yuan, Y.L.; Ma, Q.Q.; Du, M.L.; Cai, T.G.; Cai, Y. Extraction of polysaccharide from Spirulina and evaluation of its activities. Evid.-Based. Compl. Alt. 2018, 2018, 1-8. [CrossRef]

2. He, L.; Yan, X.T.; Liang, J.; Li, S.J.; He, H.R.; Xiong, Q.P.; Lai, X.P.; Hou, S.Z.; Huang, S. Comparison of different extraction methods for polysaccharides from Dendrobium officinale stem. Carbohydr. Polym. 2018, 198, 101-108. [CrossRef] [PubMed]

3. Chen, X.H.; Chen, G.J.; Wang, Z.R.; Kan, J.Q. A comparison of a polysaccharide extracted from ginger (Zingiber officinale) stems and leaves using different methods: Preparation, structure characteristics, and biological activities. Int. J. Biol. Macromol. 2020, 151, 635-649. [CrossRef] [PubMed]

4. Desai, K.; Sivakami, S. Spirulina: The wonder Food of the 21st century. Asia. Pac. Biotech. News. 2004, 8, 1298-1302. [CrossRef]

5. Chen, Y.H.; Wan, X.Z.; Wu, D.S.; Ouyang, Y.Z.; Gao, L.Y.; Chen, Z.X.; El-Seedi, H.R.; Wang, M.-F.; Chen, X.-H.; Zhao, C. Characterization of the structure and analysis of the anti-oxidant effect of microalga Spirulina platensis polysaccharide on Caenorhabditis elegans mediated by modulating microRNAs and gut microbiota. Int. J. Biol. Macromol. 2020, 163, $2295-2305$. [CrossRef] [PubMed]

6. Ma, H.T.; Xiong, H.Y.; Zhu, X.L.; Ji, C.L.; Xue, J.N.; Li, R.Z.; Ge, B.S.; Cui, H.L. Polysaccharide from Spirulina platensis ameliorates diphenoxylate-induced constipation symptoms in mice. Int. J. Biol. Macromol. 2019, 133, 1090-1101. [CrossRef]

7. Zhang, F.; Lu, J.; Zhang, J.G.; Xie, J.X. Protective effects of a polysaccharide from Spirulina platensis on dopaminergic neurons in an MPTP-induced Parkinson's disease model in C57BL/6J mice. Neural. Regen. Res. 2015, 10, 308-313. [CrossRef]

8. Mader, J.; Gallo, A.; Schommartz, T.; Handke, W.; Nagel, C.H.; Günther, P.; Brune, W.; Reich, K. Calcium spirulan derived from Spirulina platensis inhibits herpes simplex virus 1 attachment to human keratinocytes and protects against herpes labialis. J. Allergy. Clin. Immun. 2016, 137, 197-203.e3. [CrossRef]

9. Rajasekar, P.; Palanisamy, S.; Anjali, R.; Vinosha, M.; Elakkiya, M.; Marudhupandi, T.; Tabarsa, M.; You, S.G.; Prabhu, N.M. Isolation and structural characterization of sulfated polysaccharide from Spirulina platensis and its bioactive potential: In vitro antioxidant, antibacterial activity and Zebrafish growth and reproductive performance. Int. J. Biol. Macromol. 2019, 141, 809-821. [CrossRef]

10. Wu, X.Y.; Liu, Z.C.; Liu, Y.; Yang, Y.; Shi, F.L.; Cheong, K.L.; Teng, B. Immunostimulatory effects of polysaccharides from Spirulina platensis in vivo and vitro and their activation mechanism on RAW 246.7 macrophages. Mar. Drugs 2020, 18, 538. [CrossRef] [PubMed]

11. Sui, X.W.; Yin, J.C.; Ren, X.F. Antiviral effect of diammonium glycyrrhizinate and lithium chloride on cell infection by pseudorabies herpesvirus. Antivir. Res. 2010, 85, 346-353. [CrossRef]

12. Luo, P.; Liu, D.; Li, J. Pharmacological perspective: Glycyrrhizin may be an efficacious therapeutic agent for COVID-19. Int. J. Antimicrob. Agents 2020, 55, 105995. [CrossRef]

13. Liu, H.; You, L.M.; Wu, J.; Zhao, M.F.; Guo, R.; Zhang, H.L.; Su, R.; Mao, Q.; Deng, D.; Hao, Y. Berberine suppresses influenza virus-triggered NLRP3 inflammasome activation in macrophages by inducing mitophagy and decreasing mitochondrial ROS. J. Leukoc. Biol. 2020, 108, 253-266. [CrossRef] [PubMed]

14. Tai, C.J.; Jassey, A.; Liu, C.H.; Tai, C.J.; Richardson, C.D.; Wong, S.H.; Lin, L.T. Targeting autophagy augments bbr-mediated cell death in human hepatoma cells harboring hepatitis c virus RNA. Cells 2020, 9, 908. [CrossRef]

15. Yu, Y.; Shen, M.Y.; Song, Q.Q.; Xie, J.H. Biological activities and pharmaceutical applications of polysaccharide from natural resources: A review. Carbohydr. Polym. 2018, 183, 91-101. [CrossRef] [PubMed]

16. Lammi, C.; Arnoldi, A. Food-derived antioxidants and COVID-19. J. Food. Biochem. 2020, 45, e13557. [CrossRef]

17. Li, L.Y.; Huang, T.; Lan, C.; Ding, H.; Yan, C.S.; Dou, Y.L. Protective effect of polysaccharide from Sophora japonica L. flower buds against UVB radiation in a human keratinocyte cell line (HaCaT cells). J. Photoch. Photobio. B. 2018, 191, 135-142. [CrossRef] [PubMed]

18. Han, R.H.; Tang, F.T.; Lu, M.L.; Xu, C.H.; Hu, J.; Mei, M.; Wang, H.X. Astragalus polysaccharide ameliorates $\mathrm{H}_{2} \mathrm{O}_{2}$-induced human umbilical vein endothelial cell injury. Mol. Med. Rep. 2017, 15, 4027-4034. [CrossRef]

19. Zhang, L.; Hu, T.J.; Liu, H.L.; Shuai, X.H. Inhibitory effect of sargassum polysaccharide on oxidative stress induced by infectious bursa disease virus in chicken bursal lymphocytes. Int. J. Biol. Macromol. 2011, 49, 607-615. [CrossRef]

20. Hirahashi, T.; Matsumoto, M.; Hazeki, K.; Saeki, Y.; Ui, M.; Seya, T. Activation of the human innate immune system by Spirulina: Augmentation of interferon production and NK cytotoxicity by oral administration of hot water extract of Spirulina platensis. Int. Immunopharmacol. 2002, 2, 423-434. [CrossRef] 
21. Lee, R.C.; Feinbaum, R.L.; Ambros, V. The C. elegans heterochronic gene lin-4 encodes small RNAs with antisense complementarity to lin-14. Cell. 1993, 75, 843-854. [CrossRef]

22. Bartel, D.P.; Chen, C.Z. Micromanagers of gene expression: The potentially widespread influence of metazoan microRNAs. Nat. Rev. Genet. 2004, 5, 396-400. [CrossRef]

23. Bhattacharyya, S.N.; Habermacher, R.; Martine, U.; Closs, E.I.; Filipowicz, W. Relief of microRNA-Mediated Translational Repression in Human Cells Subjected to Stress. Cell. 2006, 125, 1111-1124. [CrossRef]

24. Huang, C.W.; Tsai, K.N.; Chen, Y.S.; Chang, R.Y. Differential miRNA Expression Profiling Reveals Correlation of miR125b-5p with Persistent Infection of Japanese Encephalitis Virus. Int. J. Mol. Sci. 2021, 22, 4218. [CrossRef]

25. Rahman, A.; Susmi, T.F.; Yasmin, F.; Bhattacharjee, A.; Hossain, M.U.; Das, K.C.; Keya, C.A.; Salimullah, M. Unveiling ancestral relations, host-pathogen interactions and comparative viral miRNA insights of dengue virus serotypes. Netw. Model. Anal. Health 2021, 10, 1-13.

26. Zhang, X.Q.; Li, C.; Zhang, B.Z.; Li, Z.H.; Zeng, W.; Luo, R.; Cao, J.Y.; Cheng, G.F.; Fan, S.X.; He, Q.G. Differential expression and correlation analysis of miRNA-mRNA profiles in swine testicular cells infected with porcine epidemic diarrhea virus. Sci. Rep. 2020, 11, 1868. [CrossRef]

27. Zhong, Y.X.; Du, Y.J.; Yang, X.; Mo, Y.Z.; Fan, C.; Xiong, F.; Ren, D.X.; Ye, X.; Li, C.W.; Wang, Y.M.; et al. Circular RNAs function as ceRNAs to regulate and control human cancer progression. Mol. Cancer 2018, 17, 79. [CrossRef]

28. Lin, F.; Chen, H.W.; Zhao, G.A.; Li, Y.; He, X.H.; Liang, W.Q.; Shi, Z.L.; Sun, S.Y.; Tian, P.P.; Huang, M.Y.; et al. Advances in Research on the circRNA-miRNA-mRNA Network in Coronary Heart Disease Treated with Traditional Chinese Medicine. Evid.-Based Complement. Altern. Med. 2020, 2020, 1-10. [CrossRef]

29. Sokolova, E.V.; Barabanova, A.O.; Bogdanovich, R.N.; Khomenko, V.A.; Solov'eva, T.F.; Yermak, I.M. In vitro antioxidant properties of red algal polysaccharides. Biomed. Prev. Nut. 2011, 1, 161-167. [CrossRef]

30. Bai, R.G.; Tuvikene, R. Potential antiviral properties of industrially important marine algal polysaccharides and their significance in fighting a future viral pandemic. Viruses 2021, 13, 1817.

31. Pujol, C.A.; Ray, S.; Ray, B.; Damonte, E.B. Antiviral activity against dengue virus of diverse classes of algal sulfated polysaccharides. Int. J. Biol. Macromol. 2012, 51, 412-416. [CrossRef]

32. Smirnoff, N.; Cumbes, Q.J. Hydroxyl radical scavenging activity of compatible solutes. Phytochemistry 1989, 28, 1057-1060. [CrossRef]

33. Li, B.; Zhang, N.; Wang, D.X.; Jiao, L.L.; Tan, Y.; Wang, J.; Li, H.; Wu, W.; Jiang, D.C. Structural analysis and antioxidant activities of neutral polysaccharide isolated from Epimedium koreanum Nakai. Carbohydr. Polym. 2018, 196, 246-253. [CrossRef]

34. Ye, Z.P.; Wang, W.; Yuan, Q.X.; Ye, H.; Sun, Y.; Zhang, H.C.; Zeng, X.X. Box-Behnken design for extraction optimization, characterization and in vitro antioxidant activity of Cicer arietinum L. hull polysaccharides. Carbohydr. Polym. 2016, 147, 354-364. [CrossRef]

35. Sahragard, N.; Jahanbin, K. Structural elucidation of the main water-soluble polysaccharide from Rubus anatolicus roots. Carbohydr. Polym. 2017, 175, 610-617. [CrossRef]

36. Huang, H.Y.; Liu, J.J.; Xi, R.R.; Xing, X.M.; Yuan, J.H.; Yang, L.Q.; Tao, G.H.; Gong, C.M.; Zhuang, Z.X. An investigation of hormesis of trichloroethylene in L-02 liver cells by differential proteomic analysis. Mol. Biol. Rep. 2009, 36, 2119-2129. [CrossRef]

37. Ju, T.; Xi, J. Continuous extraction optimization, molecular structures and antioxidant activities of polysaccharide from gracilariopsis lemaneiformis using liquid-phase pulsed discharge. Sep. Purif. Technol. 2020, 236, 116241. [CrossRef]

38. Chen, S.H.; Huang, H.L.; Huang, G.L. Extraction, derivatization and antioxidant activity of cucumber polysaccharide. Int. J. Biol. Macromol. 2019, 140, 1047-1053. [CrossRef]

39. Dammak, M.I.; Salem, Y.B.; Belaid, A.; Mansour, H.B.; Hammami, S.; Cerf, D.L.; Majdoub, H. Partial characterization and antitumor activity of a polysaccharide isolated from watermelon rinds. Int. J. Biol. Macromol. 2019, 136, 632-641. [CrossRef]

40. Ren, Y.P.; Liu, S.X. Effects of separation and purification on structural characteristics of polysaccharide from quinoa (chenopodium quinoa willd). Biochem. Biophys. Res. Commun. 2020, 522, 286-291. [CrossRef]

41. Jahanbin, K.; Abbasian, A.; Ahang, M. Isolation, purifification and structural characterization of a new water-soluble polysaccharide from Eremurus stenophyllus (boiss. \& buhse) baker roots. Carbohydr. Polym. 2017, 178, 386-393. [PubMed]

42. Tang, Y.; Zhu, Z.Y.; Liu, Y.; Sun, H.Q.; Song, Q.Y.; Zhang, Y.M. The chemical structure and anti-aging bioactivity of an acid polysaccharide obtained from rose buds. Food. Funct. 2018, 9, 2300-2312. [CrossRef]

43. Zhang, J.J.; Meng, G.Y.; Zhai, G.Y.; Yang, Y.H.; Zhao, H.J.; Jia, L. Extraction, characterization and antioxidant activity of polysaccharides of spent mushroom compost of Ganoderma lucidum. Int. J. Biol. Macromol. 2016, 82, 432-439. [CrossRef]

44. Zhu, Z.Y.; Liu, N.; Si, C.L.; Liu, Y.; Ding, L.N.; Jing, C.; Liu, A.J.; Zhang, Y.M. Structure and anti-tumor activity of a high-molecularweight polysaccharide from cultured mycelium of Cordyceps gunnii. Carbohydr. Polym. 2012, 88, 1072-1076. [CrossRef]

45. Chaiklahan, R.; Chirasuwan, N.; Triratana, P.; Loha, V.; Tia, S.; Bunnag, B. Polysaccharide extraction from Spirulina sp. and its antioxidant capacity. Int. J. Biol. Macromol. 2013, 58, 73-78. [CrossRef]

46. Steinhorn, G.; Sims, I.M.; Carnachan, S.M.; Carr, A.J.; Schlothauer, R. Isolation and characterisation of arabinogalactan-proteins from new zealand kanuka honey. Food. Chem. 2011, 128, 949-956. [CrossRef]

47. Li, J.; Zhang, Y.Q.; Yang, S.; Lu, Z.H.; Li, G.L.; Liu, J.W.; Zhou, B.; Wu, D.R.; Wang, L. Isolation, Purification, Characterization, and Immunomodulatory Activity Analysis of $\alpha$-Glucans from Spirulina platensis. ACS. Omega 2021, 6, 21384-21394. [CrossRef] 
48. Nie, C.Z.P.; Zhu, P.L.; Ma, S.P.; Wang, M.C.; Hu, Y.D. Purification, characterization and immunomodulatory activity of polysaccharides from stem lettuce. Carbohydr. Polym. 2018, 188, 236-242. [CrossRef]

49. Sun, Z.L.; Peng, Y.; Zhao, W.W.; Xiao, L.L.; Yang, P.M. Purification, characterization and immunomodulatory activity of a polysaccharide from Celosia cristata. Carbohydr. Polym. 2015, 133, 337-344. [CrossRef]

50. Wang, M.L.; Hou, Y.Y.; Chiu, Y.S.; Chen, Y.H. Immunomodulatory activities of Gelidium amansii gel extracts on murine RAW 264.7 macrophages. J. Food. Drug. Anal. 2013, 21, 397-403. [CrossRef]

51. Jiang, Y.P.; Zi, W.; Pei, Z.F.; Liu, S. Characterization of polysaccharides and their antioxidant properties from Plumula nelumbinis. Saudi. Pharm. J. 2018, 26, 656-664. [CrossRef]

52. Antunes, M.A.; Lopes-Pacheco, M.; Rocco, P.R.M. Oxidative stress-derived mitochondrial dysfunction in chronic obstructive pulmonary disease: A concise review. Oxid. Med. Cell. Longev. 2021, 2021,1-11. [CrossRef]

53. Yalcinkaya, T.; Uzilday, B.; Ozgur, R.; Turkan, I.; Mano, J. Lipid peroxidation-derived reactive carbonyl species (RCS): Their interaction with ROS and cellular redox during environmental stresses. Environ. Exp. Bot. 2019, 165, 139-149. [CrossRef]

54. Chen, S.; Chen, H.S.; Du, Q.H.; Shen, J.G. Targeting myeloperoxidase (MPO) mediated oxidative stress and inflammation for reducing brain ischemia injury: Potential application of natural compounds. Front. Physiol. 2020, 11, 433. [CrossRef]

55. Zhang, C.; Zhang, G.W.; Liao, Y.J.; Gong, D.M. Myricetin inhibits the generation of superoxide anion by reduced form of xanthine oxidase. Food. Chem. 2017, 221, 1569-1577. [CrossRef]

56. Fernandes, I.G.; Brito, C.A.D.; Reis, V.M.S.D.; Sato, M.N.; PereiRa, N.Z. SARS-CoV-2 and other respiratory viruses: What does oxidative stress have to do with it? Oxid. Med. Cell. Longev. 2020, 2020,1-13. [CrossRef]

57. Zeraik, M.L.; Serteyn, D.; Deby-Dupont, G.; Wauters, J.N.; Tits, M.; Yariwake, J.H.; Angenot, L.; Franck, T. Evaluation of the antioxidant activity of passion fruit (Passiflora edulis and Passiflora alata) extracts on stimulated neutrophils and myeloperoxidase activity assays. Food. Chem. 2011, 128, 259-265. [CrossRef]

58. Liao, Z.Z.; Zhang, J.Y.; Liu, B.; Yan, T.X.; Xu, F.X.; Xiao, F.; Wu, B.; Bi, K.S.; Jia, Y. Polysaccharide from okra (abelmoschus esculentus (1.) moench) improves antioxidant capacity via pi3k/akt pathways and nrf2 translocation in a type 2 diabetes model. Molecules. 2019, 24, 1906. [CrossRef]

59. Li, Q.L.; Chen, N.; Cai, H.; Tang, Y.; Zhou, X.Y.; Huang, Y.; Gong, M.X.; Qin, C.Y.; Wei, X.W.; Qi, S.H. Analysis of momordica charantia polysaccharide components and their effects on ka-induced oxidative stress and neuronal loss in the hippocampus of epileptic rats. World. J. Neurosci. 2018, 8, 113-123. [CrossRef]

60. Pang, F.; Zhang, M.M.; Yang, X.J.; Li, G.H.; Zhu, S.; Nie, X.; Cao, R.Y.; Yang, X.H.; Zhang, Z.X.; Huang, H.F.; et al. Genome-wide analysis of circular RNAs in goat skin fibroblast cells in response to Orf virus infection. PeerJ. 2019, 7, e6267. [CrossRef]

61. Zhao, W.; Su, J.Y.; Wang, N.N.; Zhao, N.Y.; Su, S. Expression Profiling and Bioinformatics Analysis of CircRNA in Mice Brain Infected with Rabies Virus. Int. J. Mol. Sci. 2021, 22, 6537. [CrossRef] [PubMed]

62. Yang, T.; Qiu, L.L.; Bai, M.; Wang, L.D.; Hu, X.D.; Huang, L.; Chen, G.H.; Chang, G.B. Identification, biogenesis and function prediction of novel circRNA during the chicken ALV-J infection. Anim. Biotechnol. 2020, 10, 1-11.

63. Zhang, H.L.; Chen, Z.M.; Zhong, Z.Y.; Gong, W.F.; Li, J. Total saponins from the leaves of Panax notoginseng inhibit depression on mouse chronic unpredictable mild stress model by regulating circRNA expression. Brain. Behav. 2018, 8, e01127. [CrossRef] [PubMed]

64. Salzman, J.; Gawad, C.; Wang, P.L.; Lacayo, N.; Brown, P.O. Circular RNAs Are the Predominant Transcript Isoform from Hundreds of Human Genes in Diverse Cell Types. PLoS ONE 2012, 7, e30733. [CrossRef] [PubMed]

65. Werfel, S.; Nothjunge, S.; Schwarzmayr, T.; Strom, T.M.; Meitinger, T.; Engelhardt, S. Characterization of circular RNAs in human, mouse and rat hearts. J. Mol. Cell Cardiol. 2016, 98, 103-107. [CrossRef] 